\title{
Property rights and loss aversion in contests
}

\section{Article}

Accepted Version

Chowdhury, S. M., Jeon, J. Y. and Ramalingam, A. (2018) Property rights and loss aversion in contests. Economic Inquiry, 56 (3). pp. 1492-1511. ISSN 1465-7295 doi: https://doi.org/10.1111/ecin.12505 Available at https://centaur.reading.ac.uk/73402/

It is advisable to refer to the publisher's version if you intend to cite from the work. See Guidance on citing.

To link to this article DOI: http://dx.doi.org/10.1111/ecin.12505

Publisher: Wiley

All outputs in CentAUR are protected by Intellectual Property Rights law, including copyright law. Copyright and IPR is retained by the creators or other copyright holders. Terms and conditions for use of this material are defined in the End User Agreement.

\section{www.reading.ac.uk/centaur}

\section{CentAUR}

Central Archive at the University of Reading

Reading's research outputs online 


\title{
Property Rights and Loss Aversion in Contests *
}

\author{
Subhasish M. Chowdhury ${ }^{\mathrm{a}}$, Joo Young Jeon ${ }^{\mathrm{a}}$ and Abhijit Ramalingam ${ }^{\mathrm{b}}$ \\ ${ }^{\text {a }}$ School of Economics, Centre for Behavioural and Experimental Social Science, and Centre \\ for Competition Policy, University of East Anglia, Norwich NR4 7TJ, UK. \\ ${ }^{\mathrm{b}}$ School of Economics, and Centre for Behavioural and Experimental Social Science, \\ University of East Anglia, Norwich NR4 7TJ, UK.
}

June 09, 2017

\begin{abstract}
We analyze the effects of property rights and the resulting loss aversion on contest outcomes. We study three situations: in 'gain' two players start with no prize and make sunk bids to win a prize, whereas in 'loss' both the players start with prizes and whoever loses the contest loses their prize. Finally, in 'mixed' only one player starts with a prize that stays with him if he wins, but is transferred to the rival otherwise. Since the differences among the treatments arise only from framing, the expected utility model and the standard loss aversion model predict no difference in bids across treatments. We introduce a loss aversion model in which the property rights are made salient, and as a result the reference point varies across treatments. This model predicts average bids in descending order in the loss, the mixed, and the gain treatment; and higher bids by the player with property rights in the mixed treatment. The results from a laboratory experiment broadly support these predictions. In the laboratory, no significant difference is found in bids in the loss (gain) treatment versus bids by property rights holder (non-holder) in the mixed treatment. A model incorporating both loss aversion and social preferences explains this result.
\end{abstract}

JEL Classifications: C91, C72, D23, D74

Keywords: Contest; Experiment; Framing; Property-rights; Loss Aversion

* Corresponding author: Joo Young Jeon (j.jeon@uea.ac.uk)

We thank two anonymous referees, Mike Brock, Paul Gorny, Oliver Gurtler, Ian Hardy, Erik Kimbrough, Henrik Orzen, Dmitry Ryvkin, Santiago Sanchez-Pages, Roman Sheremeta, Bob Sugden, participants at the 2016 EARC Workshop on Conflict, 2016 CBESS Conference on Contests: Theory and Evidence, $21^{\text {st }}$ Tax Day workshop at the MPI Munich, 2017, Game Theory Conference at Lancaster, and seminar participants at the Universities of Bath, Durham, East Anglia, Tromso and Yonsei for useful comments. Any remaining errors are our own. 


\section{Introduction}

Conflicts are ubiquitous. Examples of conflict range from war, terrorism, crime, political clashes, to rent seeking, sports, computer security, and legal battles. The analysis of conflicts - both theoretically and in the field - has consequently attracted substantial attention from economists. In any conflict, the parties involved expend costly resources to earn a gain or to avoid a loss. Irrespective of the outcome, the resources spent cannot be recovered. This enables one to use the tools of contest theory (see, e.g., Konrad, 2009) to analyze conflict situations.

Private property rights (Alchian and Demsetz, 1973) and related issues of loss aversion - weighing loss more than gain (Kahneman and Tversky, 1979) - are arguably some of the most important elements that determine the intensity of conflict. Disputes over property rights have been the source of conflict since the start of the civilization. The Indian Epic Mahabharata (see Smith, 2009) written in about 900 BC, for example, centers on the specific issue of property rights and the resulting conflict among kingdoms. More recent examples include conflicts between the UK and Argentina over the Falkland Islands, between China, Philippines, Viet Nam and several other countries in the South China Sea and between Israel and Syria over Golan Heights. Such conflicts even exist in the animal kingdom. For example, when a parasitic wasp captures a host and tries to lay eggs; often another wasp tries to invade the host. Stockermans and Hardy (2013) and Humphries et al. (2006) use complementary approaches to show that those wasps who value the host most will fight harder and win more often. The phenomenon of loss aversion is also observed in international conflicts where the observed long status quos are often attributed to loss aversion (Levy, 1996). Zamir and Ritov (2012) argue in the law literature that it is efficient for the burden of proof in civil litigation to be on the plaintiff due to the presence of loss aversion. Loss aversion can be observed in sports contests as well. Lee (2004), for example, finds that the professional players in the World Poker Tour are more sensitive to losses than gains. Finally, Petersen \& Hardy (1996) show that in the owner-intruder contests among wasps, the owner is advantaged, whereas Stokkebo and Hardy (2000) show that this is because egg load affects resource value perception (i.e., loss aversion).

Existing research has focused on how property rights and conflict affect growth (e.g., Skaperdas, 1992; Hafer, 2006). However, some important aspects have received little attention in the literature. First, the effects of property rights on conflict intensity has hitherto not been theorized. Second, a behavioral foundation for the effect of property rights is lacking. Third, since it is difficult to obtain data from the field, there is little empirical evidence. 
In this study we analyze the effects of property rights on conflict intensity. We model conflicts as contests and theorize that property rights invoke loss aversion. We derive testable predictions using both an expected utility model and a model with loss aversion (plus a further one with loss aversion and social preferences). Then we implement a laboratory experiment and test the hypotheses obtained from the theoretical models. In one treatment of the experiment, the two-player contest game is framed in a gain domain, in another it is framed in a loss domain, and in the final treatment it is framed in the gain domain for one player and in the loss domain for the other player. Our novel model with loss aversion provides a clear ranking of equilibrium bids (or efforts) by subjects whereas standard theories predict equal equilibrium bids in the different treatments. Experimental results support the prediction of loss aversion, whereby bids in a loss frame are significantly higher than bids in a gain frame. Whereas other rankings are preserved qualitatively, they are not statistically significant. A behavioral model rationalizes these findings.

While the independent literatures on property rights, loss aversion and contests are huge, their intersection is thin. ${ }^{1}$ Loss aversion is a human tendency to strongly prefer avoiding losses to acquiring gains. Hence ownership of a valuable object understandably brings an aversion to losing that object. Property rights, thus, have a specific behavioral effect on the rights holder. The holder of the property rights might experience loss aversion (Tversky and Kahneman, 1991), whereas the non-holder might not. A series of studies following Kahneman et al. (1991) explore the difference between willingness to pay and willingness to accept, and attribute the difference to loss aversion or an endowment affect. Hoffman et al. (1996) show that dictators' behavior is close to Nash equilibrium if they earn the endowment to be shared. This is also attributed to loss aversion or endowment effects. The application of the same notions in conflict or contests, however, is more recent.

Contest theory analyzes situations in which players make costly bids in order to affect the probability of winning a prize. Given the real life implications of property rights and loss aversion in conflicts - often modeled as a contest - contest researchers were interested in this topic. Cornes and Hartley $(2003,2012)$ are the first to investigate this issue. They show theoretically that, with loss aversion, bids in a contest are lower. Kolmar (2008) uses a rent seeking contest with an endogenously produced rent to investigate endogenously enforced property rights as incentives for efficient production. Gill and Stone (2010) include loss

\footnotetext{
${ }^{1}$ Various dimensions and the effects of property rights are investigated in the law and economics, and in the innovation literatures. Since our aim is very different from the aims of such literature, we do not cover them here. Interested readers may consult Barzel (1997) or Colombatto (2004) for references.
} 
aversion in a tournament model with endogenous reference points and find identical players end up closer to their reference points. Morgan and Sisak (2015) show that the fear of losing may elicit higher bids in "winner takes all" investment games.

The first experiment in this area is by Kong (2008) who implements a lottery contest experiment and elicits loss aversion with a survey. Supporting the result from Cornes and Hartley (2003), Kong (2008) shows that bids are decreasing in the degree of loss aversion. This is reiterated in Falk et al. (2008) who show that a larger prize spread might reduce bids in a tournament due to loss aversion. These, along with a further string of studies (Gill and Prowse, 2012; Ernst and Thöni, 2013; Shupp et al., 2013; Price and Sheremeta, 2015; Sheremeta, 2016) find the general result that loss aversion leads to a lower level of bids in contests. Eisenkopf and Teyssier (2013) use a tournament model and, instead of a winner-take-all probability, they implement a prize-sharing rule as a function of the bids made. They show that this frame eliminates loss aversion. Dutcher et al. (2015) use the same explanatory variable as in Kong (2008) and find contradictory results.

In contrast, we show theoretically and experimentally that property rights and the resulting loss aversion can result in higher bids in contests. Thus, in this study we make a threefold contribution. First, and most importantly, we are the first to show how loss aversion can result in more aggressive bidding in contests. Second, the current study along with Kimbrough and Sheremeta (2014), and Price and Sheremeta (2015) are the earliest studies that connect the issue of property rights to behavior in contests. Finally, we are the first to document framing effects in contest experiments, and provide a behavioral explanation of the results.

The rest of the paper proceeds as follows. In the next section we describe the treatments and derive theoretical predictions and related hypotheses. Section 3 describes the details of the experimental procedure. We report the results in Section 4. Section 5 describes a behavioral model that further better explains some experimental results, and Section 6 concludes.

\section{Treatments, theory and hypotheses}

In this section we first describe the different situations related to property rights and conflict and match them with the three treatments of this study. Next, we provide a theoretical background and the predictions generated by the expected utility theory, standard theory with loss aversion, and a theory with loss aversion in which salient property rights affect the reference point. We then present hypotheses arising from these theoretical predictions.

In standard contest experiments, subjects start with no prize and make costly and irreversible bids to affect the likelihood of winning a prize. This essentially portrays situations 
in which none of the players hold property rights and they engage in conflict to gain the property rights to the prize. Various contests such as sports, rent-seeking or innovation tournaments can be modeled in this way. We keep this gain frame as the baseline and introduce two further treatments. We first consider the polar opposite case in which both the players hold property rights to a prize, but may lose these due to the outcome of the conflict. Hence, in the loss frame we allow both the subjects to start with prizes and place bids. The winner gets to keep the prize but whoever loses the contest loses his prize. A number of contests such as the case of downsizing due to performance, elimination tournaments, or the fight between two gladiators in the amphitheater (the loser loses his right to life) exemplify this frame. In the final treatment we consider the case where one of the players holds property rights that he may lose, whereas the other player does not hold property rights, but may gain it as an outcome of the conflict. In this mixed frame, one of the subjects starts with a prize whereas the other starts with no prize. The prize stays with the subject-with-prize if he wins, and is transferred to the subjectwithout-prize otherwise. Examples given in the introduction, including that of the wasp and conflicts between countries, or a boxing title match (in which the current champion holds the title, but may lose it to the challenger) are eminent field examples of this frame.

In the laboratory we implement the above three treatments in a two-player Tullock (1980) contest. Each player has initial resource $E$ that can be spent in the contest. Let player $i$ bid $b_{i} \in[0, E]$. Irrespective of the outcome of the contest, players forgo their bids. The probability that player $i$ wins is represented by a Tullock (1980) contest success function:

$p_{i}\left(b_{1}, b_{2}\right)=\left\{\begin{array}{cl}b_{i} /\left(b_{1}+b_{2}\right) & \text { if }\left(b_{1}+b_{2}\right) \neq 0 \\ 1 / 2 & \text { otherwise }\end{array}\right.$ and $\sum_{i} p_{i}\left(b_{1}, b_{2}\right)=1$

Given the contest success function, we now formally introduce the treatments below.

Gain Treatment. None of the players holds initial property rights to a prize and hence both start with no prize. They compete to win a prize of common value $V>0$ that is gained by the winner, but there is no prize for the loser. The payoff function of player $i$ is:

$\pi_{i}\left(b_{1}, b_{2}\right)= \begin{cases}V+\left(E-b_{i}\right) & \text { with prob } p_{i}\left(b_{1}, b_{2}\right) \\ 0+\left(E-b_{i}\right) & \text { with prob } 1-p_{i}\left(b_{1}, b_{2}\right)\end{cases}$

Loss Treatment. Both players hold initial property rights to the prize, and consequently each player starts with a prize of common value $V>0$. Post contest, the winner gets to keep his prize but the loser must relinquish theirs. The payoff function of player $i$ is: 
$\pi_{i}\left(b_{i}, b_{-i}\right)= \begin{cases}V+\left(E-b_{i}\right)-0 & \text { with prob } p_{i}\left(b_{1}, b_{2}\right) \\ V+\left(E-b_{i}\right)-V & \text { with prob } 1-p_{i}\left(b_{1}, b_{2}\right)\end{cases}$

Mixed Treatment. Without loss of generality assume that player 1 holds the initial property rights for a prize but player 2 does not. Hence, player 1 starts with the prize of common value $V>0$ and player 2 does not start with any prize. After the contest, if player 1 is the winner then he gets to keep his prize. But if player 2 is the winner then the prize is transferred to them. Hence, the payoff functions of the players are:

$\pi_{1}\left(b_{1}, b_{2}\right)= \begin{cases}V+\left(E-b_{1}\right)-0 & \text { with prob } p_{1}\left(b_{1}, b_{2}\right) \\ V+\left(E-b_{1}\right)-V & \text { with prob } 1-p_{1}\left(b_{1}, b_{2}\right)\end{cases}$

$\pi_{2}\left(b_{1}, b_{2}\right)= \begin{cases}V+\left(E-b_{2}\right) & \text { with prob } 1-p_{1}\left(b_{1}, b_{2}\right) \\ 0+\left(E-b_{2}\right) & \text { with prob } p_{1}\left(b_{1}, b_{2}\right)\end{cases}$

Note that once we set $V-V=0$, the payoff functions in (2), (3), (4A) and (4B) are the same. Hence, under risk neutrality and assuming no loss aversion, the expected payoff of player $i, E\left(\pi_{i}\right)$ for $i=1,2$, in each of the cases becomes:

$E\left(\pi_{i}\right)=p_{i} V+\left(E-b_{i}\right)$

The existence and uniqueness of the equilibrium for this game are proved by Szidarovszky and Okuguchi (1997). Following standard procedures (e.g., Chowdhury and Sheremeta, 2011), the unique and symmetric Nash equilibrium bid is $b^{*}=V / 4$ and the equilibrium payoff is $\pi^{*}=E+V / 4 .^{2}$ Note that the equilibrium bid, when one does not consider loss aversion, does not depend on the initial endowment or on the specific treatment.

Cornes and Hartley (2012) introduce the standard version of a loss aversion model in a Tullock contest in which the players "value gains less than losses of similar magnitude". There may exist multiple equilibria, but for the specific two-player symmetric lottery case we are concerned with, Cornes and Hartley (2012) show that the equilibrium is unique. Again, since the payoff functions are the same in (2), (3), (4A) and (4B), the equilibrium bids are also the same for the three treatments. However, the authors find that the equilibrium bid is lower in magnitude than the equilibrium bid under no loss aversion (i.e., $b_{\text {loss-aversion }}^{*}<V / 4$ ). ${ }^{3}$

Let us denote the bids in the Gain frame as $b_{G}$, bids in the Loss frame as $b_{L}$, bids by the holder of the property rights in the Mixed frame as $b_{M L}$, and the bids by the player with no

\footnotetext{
${ }^{2}$ A requirement for this equilibrium is $E \geq V / 4$, which we ensure in our experimental design.

${ }^{3}$ For this two-player case, see Sheremeta (2013) for an easier version of the proof.
} 
property rights in the Mixed frame as $b_{M G}$. Since we are interested in treatment effects and not bid levels, we can combine the predictions from the standard expected utility and Cornes and Hartley (2012) type loss aversion models. Then the predictions are:

$b_{G}=b_{L}=b_{M L}=b_{M G}$

As an alternative, we propose a variation of the loss aversion model focusing on the salience of the property rights. Our experimental design relies solely on such salience through framing; which, in turn, induces loss aversion over the property rights to the prize. Hence, we implement a standard model of loss aversion where the utility of player $i\left(u_{i}\right)$ is piece-wise linear about a reference point, $R$, and the players maximize their expected utility.

$u_{i}= \begin{cases}\pi_{i} & \text { if } \pi_{i} \geq R \\ R+\lambda\left[\pi_{i}-R\right] & \text { if } \pi_{i}<R\end{cases}$

where $\lambda>1$ is the loss aversion parameter.

The reference point $R$ is the earnings 'before' the resolution of uncertainty. Hence, the natural reference point given the way the payoffs are structured, and are presented in the experiment would be:

$R= \begin{cases}{\left[V+\left(E-b_{i}\right)\right]} & \text { for the property right holder } \\ \left(E-b_{i}\right) & \text { for the property right non }- \text { holder }\end{cases}$

Once we incorporate Eq. 8 in Eq. 7 and consider the Gain (no initial property rights) treatment, after some manipulation the utility function becomes the same as the payoff function in Eq. 2:

$$
u_{i}\left(b_{1}, b_{2}\right)= \begin{cases}V+\left(E-b_{i}\right) & \text { with prob } p_{i}\left(b_{1}, b_{2}\right) \\ 0+\left(E-b_{i}\right) & \text { with prob } 1-p_{i}\left(b_{1}, b_{2}\right)\end{cases}
$$

As a result, the expected utility becomes the same as the expected payoff (Eq. 5) in the 'no loss aversion' case. Hence, the equilibrium bid also remains the same: $b_{G}=V / 4$.

However, when we consider the Loss (initial property rights) treatment and run the necessary manipulations, the utility function (corresponding to Eq. 3) becomes:

$u_{i}\left(b_{i}, b_{-i}\right)= \begin{cases}V+\left(E-b_{i}\right) & \text { with prob } p_{i}\left(b_{1}, b_{2}\right) \\ V+\left(E-b_{i}\right)-\lambda V & \text { with prob } 1-p_{i}\left(b_{1}, b_{2}\right)\end{cases}$

And the corresponding expected utility becomes:

$E\left(u_{i}\right)=p_{i} \lambda V+\left((1-\lambda) V+E-b_{i}\right)$ 
Applying standard procedures, the unique Nash equilibrium bid is: $b_{L}=\lambda V / 4$.

Note that these reduced form utility functions can be interpreted simply as considering the 'gain value' at $V$ while considering the 'loss value' at $\lambda V>V$. The case for the Mixed treatment then similarly follows. Here the expected utility for the property rights holder is depicted by Eq. 11, while the expected utility for the player with no property rights is depicted by Eq. 2 . Solving for equilibrium provides the following equilibrium bids: $b_{M G}=\lambda V /(1+\lambda)^{2}$ and $b_{M L}=\lambda^{2} V /(1+\lambda)^{2}$.

Note that the average equilibrium bid in the Mixed treatment is $\overline{b_{M}}=\left[b_{M G}+b_{M L}\right] / 2=$ $\left[\lambda V /(1+\lambda)^{2}+\lambda^{2} V /(1+\lambda)^{2}\right] / 2=\lambda V / 2(1+\lambda)$. Given $\lambda>1$, it is thus easy to observe that $\lambda V / 4>\lambda V / 2(1+\lambda)>V / 4$. This gives us the first hypothesis that there is a clear ranking among average bids across different treatments. In specific, the average bid in the Mixed treatment lies in between the average (or individual) bids in the Loss and the Gain treatments.

Hypothesis 1: $b_{L}>\overline{b_{M}}>b_{G}$.

It is also easy to observe that, given $\lambda>1$, the bids by players with property rights are higher than the bids by the players without property rights in the Mixed treatment. This gives the next Hypothesis.

\section{Hypothesis 2: $b_{M L}>b_{M G}$.}

Lastly, it can be observed after some manipulation that there is a ranking among the bids of the four different types of players: $\lambda V / 4>\lambda^{2} V /(1+\lambda)^{2}>V / 4>\lambda V /(1+\lambda)^{2}$. This provides our next hypothesis that players with (without) property rights in the Loss (Gain) treatment bid more than their counterpart in the Mixed treatment:

Hypothesis 3: $b_{L}>b_{M L}$ and $b_{G}>b_{M G}$.

Recall that the Cornes and Hartley (2012) model (with standard loss aversion but no property rights) predicts lower bids with loss-aversion than without loss-aversion. However, this model suggests no difference across treatments because the reference point in this model is the initial endowment that remains constant across treatments. Contrary to this, our model finds a positive effect of loss aversion on bids because the reference point changes in our model depending on whether a player holds the property rights or not.

A diagrammatic description of the hypotheses is given in Figure 1 where the $X$-axis $(Y$ axis) depicts the bids of Player 1 (Player 2). Consider 4 cases: Player 1 holds or does not hold property rights vs. Player 2 holds or does not hold property rights. The parabolas are best 
response functions of the players: e.g., the large dotted parabola $b_{1 L}\left(b_{2}\right)$ is the best response of Player 1 when he holds property rights. An equilibrium is achieved at the intersection of the best response functions of the two players. Observe that the bid by Player 1 when both he and the rival hold property rights, $b_{L}$, is greater than the bid $b_{M L}$, when he holds property rights but his rival does not. This, in turn is greater than the bid $b_{G}$, when none hold property rights. The bid $b_{M G}$, when Player 1 does not hold property rights but his rival does, is the smallest.

Figure 1. Equilibrium bid with property rights and loss aversion

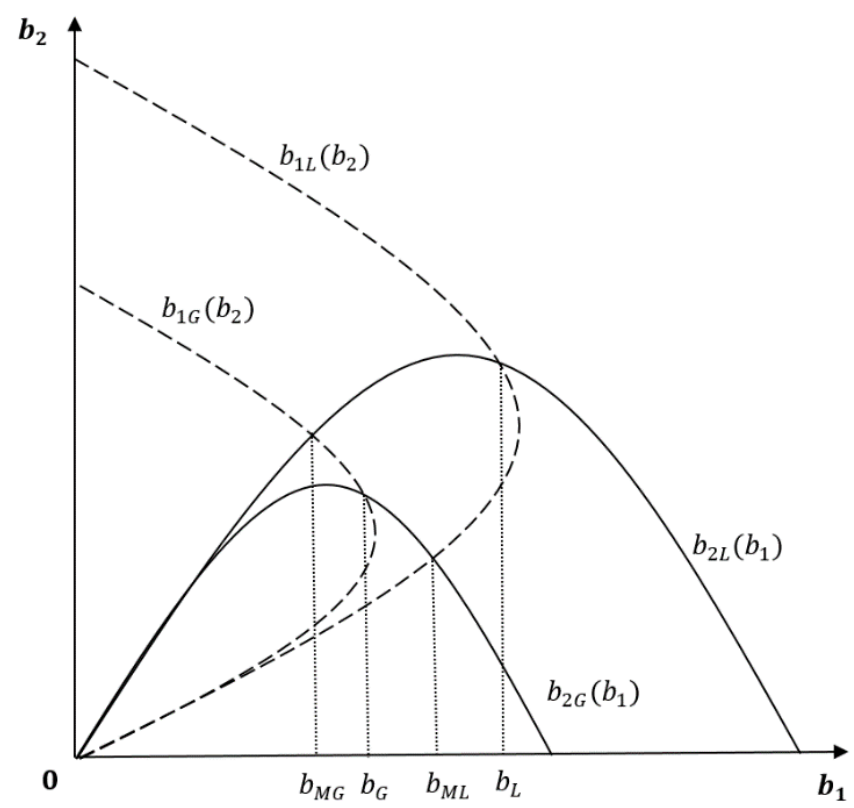

The intuition behind this ranking is simple. As shown in the reduced form utility functions, in the Loss frame both the players perceive loss with higher weight. However, in Mixed, only the property rights holder does so. Due to the asymmetry, the response of the property rights holder to other player's bid is not as high as the case when both face loss aversion. Similarly, the ranking in Hypothesis 3 appears due to asymmetry in player type in the Mixed treatment. Put another way, when a player with no property rights faces one with property rights, he reduces his bid.

\section{Experimental procedures}

The experiment was computerized using z-Tree (Fischbacher, 2007) and was run in a laboratory of the Centre for Behavioural and Experimental Social Science at the University of East Anglia. The subjects were students at the University and were recruited through the online recruiting system ORSEE (Greiner, 2015). We employed a fixed matching protocol meaning that in each session two subjects were randomly matched into one group of contestants and the 
matching did not change in a session. We implemented a fixed matching since each pair of subjects under this protocol constitutes one independent observation, but a random matching protocol gives only one independent observation per session. Forty-four subjects participated in each of the Loss and the Gain treatments (22 independent observations each) and 88 subjects in the Mixed treatment (44 independent observations). This is because in the last treatment we have 44 subjects who hold property rights and the remaining 44 subjects do not.

In all the treatments, two players compete for a prize of 180 tokens, i.e., $V=180$. Hence, the expected utility equilibrium bid $\left(b^{*}\right)$ per period is 45 tokens in all treatments. This remains the same in finite repetitions of the one-shot game, but repetition allows us to control for learning. Each player receives a budget of 180 tokens in each period, and can enter bids up to one decimal place. While players compete in each of 25 periods, they are paid the average earning of five randomly chosen periods. All subjects in a session are paid for the same five rounds. We implement such payment scheme since paying for all the periods may trigger accumulated wealth effect over the periods; whereas if we pay only one period, then the payoff dispersion among subjects is likely to be large. Table 1 summarizes the treatment details.

Table 1. Treatment specification

\begin{tabular}{lccccc}
\hline Treatment & $\begin{array}{c}\text { Budget / } \\
\text { period }(\boldsymbol{E})\end{array}$ & $\begin{array}{c}\text { Players / } \\
\operatorname{group}(\boldsymbol{N})\end{array}$ & $\begin{array}{c}\text { Prize value } \\
(\boldsymbol{V})\end{array}$ & $\begin{array}{c}\text { Expected Utility } \\
\text { Eqbm bid }\left(\boldsymbol{b}^{*}\right)\end{array}$ & $\begin{array}{c}\text { Total no. } \\
\text { of } \\
\text { subjects }\end{array}$ \\
\hline Gain & 180 & 2 & 180 & 45 & 44 \\
Loss & 180 & 2 & 180 & 45 & 44 \\
Mixed & 180 & 2 & 180 & 45 & 88 \\
\hline
\end{tabular}

We implemented instructions for the Gain and Loss treatments that closely correspond to Eq. 2 and Eq. 3. For example, in the Gain treatment it is spelled out that if they receive the reward then the earning is = Endowment + Reward - bid. However, if they do not receive the reward then the earning is = Endowment - bid. For the Loss treatment, the subjects were told that each of them starts with a reward, but they might lose it. If they keep the reward then the earning is $=($ Endowment + Reward $)-$ bid -0 ; but if they lose the reward then the earning is $=$ (Endowment + Reward) - bid - Reward. Similarly, for the Mixed treatment the instructions closely followed Eq. 4A and 4B. Subjects were told that one of the subjects in each subject pair starts with a reward whereas the other does not. If the reward holder wins the contest, then he gets to keep his reward, but if the non-holder wins the contest, then the reward is transferred to 
the non-holder. Further, the same player started with the reward in each period. Please see Appendix II for the instructions used in the experiment.

Each subject participated in only one of the sessions and no subject had previously participated in any contest or loss aversion experiment. Before the contest part, a risk elicitation task a la Eckel and Grossman (2008) was run, but the outcome of this task was not revealed until the end of the experiment. Instructions were read aloud by an experimenter, after which subjects answered a quiz before they could proceed to the experiment. Before the payment was made, subject demographic information were collected through an anonymous survey. Each session took around 45 minutes. At the end of each session the token earnings were converted to GBP at the rate of 1 token to 3 Pence. Subjects on average earned about $£ 8.40$.

\section{Results}

We first report the results aggregated at the treatment level, and test Hypothesis 1. We then move on to analyze bids at the individual level and test Hypotheses 2 and 3. In each case, we report descriptive statistics before running non-parametric tests or panel regressions.

\subsection{Aggregate results}

Table 2 presents descriptive statistics of bids in the three treatments. We run z-tests (Wilcoxon ranksum tests) that confirm the common phenomenon in Tullock experiments (see Dechenaux et al., 2015) that average bids in each treatment are higher than the equilibrium bid of 45 (pvalues $<0.05$ in each test). Moreover, a Kruskal Wallis test also confirms that the distributions of bids are different across treatments (chi-squared $=8.379$ with 2 d.f.; $p=0.015$ ), rejecting the prediction from the expected utility model (Eq. 6).

Table 2. Descriptive statistics of bids across subject-pairs per treatment

\begin{tabular}{lccc}
\hline & Obs & Mean & St Dev \\
\hline Gain & 22 & 53.747 & 19.426 \\
Loss & 22 & 71.901 & 17.858 \\
Mixed & 44 & 62.662 & 22.112 \\
\hline
\end{tabular}

Observe that there is a clear ranking of average bids across treatments. The mean bid in Gain treatment is 53.7; this increases to 62.7 in the Mixed treatment and to 71.9 in the Loss treatment. To understand if this is a common phenomenon over the time-periods, we plot the trends in average individual bids over the 25 periods in Figure 2. 
Figure 2. Average individual bids over time

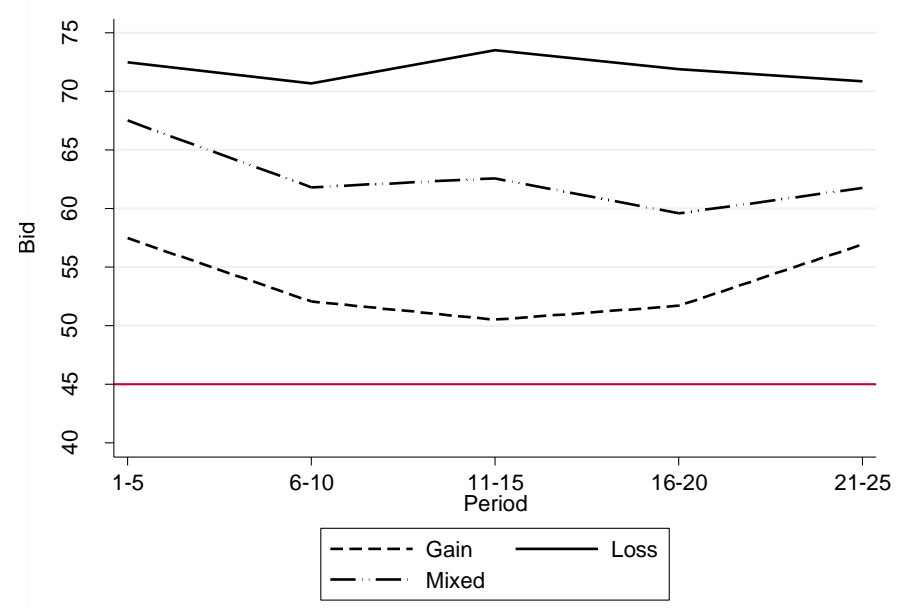

Figure 2 shows that this ranking remains stable over the 25 periods (the horizontal line is the equilibrium bid at 45). Hence, the data, at least qualitatively, support Hypothesis 1 . To test this formally we run pairwise Wilcoxon tests (reported in Table 3).

Table 3. Pairwise comparison of treatments: Two-sided Wilcoxon tests

\begin{tabular}{lcc}
\hline & Loss Frame & Mixed Frame \\
\hline Gain Frame & $-2.887^{* *}$ & -1.551 \\
& {$[0.040]$} & {$[0.121]$} \\
Loss Frame & - & $1.768^{*}$ \\
& & {$[0.077]$} \\
\hline
\end{tabular}

Note: Figures in brackets are p-values; $* *$ and $*$ denote significance at the $5 \%$ and $10 \%$ levels.

The tests confirm significant differences between Loss and Gain, and between Loss and Mixed; but the difference between the Gain and Mixed is marginally insignificant at the conventional level ( $\mathrm{p}$-value $=0.12)$. This gives our first result.

Result 1: Average bids in the Loss treatment are significantly higher than average bids in the Gain and the Mixed treatment. However, differences in average bids between the Gain and the Mixed treatment are not significant at the conventional level.

This result broadly supports Hypothesis 1, and confirms the effects of loss aversion through property rights. Note that our model with loss aversion does not include the social preferences of the subjects. However, social preferences - especially spite - might explain the no-difference result between Gain and Mixed. In Section 5 we develop a behavioral model with social preferences that explains this finding. 


\subsection{Individual level results: with and without property rights}

We next investigate if there are differences in behavior between the holders and non-holders of property rights within the Mixed treatment. Moreover, we investigate whether property rights holders (or non-holders) behave in the same way in a 'pure' treatment and in the Mixed treatment. Similar to Figure 1, Figure 2 presents the time trend of mean individual bids. The left (right) panel of Figure 2 presents bids of those with (without) property rights in the Mixed treatment and those in the Loss (Gain) treatment. Similarly, Table 4 now splits the descriptive statistics of the Mixed treatments into the holder and non-holder of property rights.

Figure 3. Average bid over time

(a) Holders of property rights

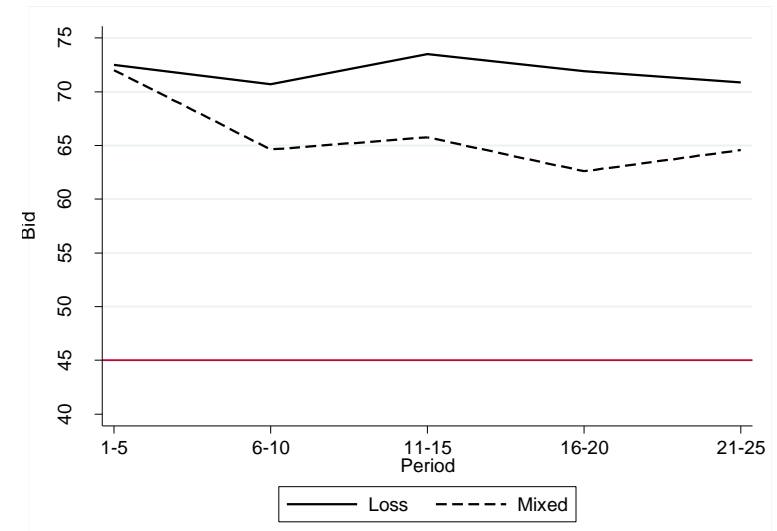

(b) Non-holders of property rights

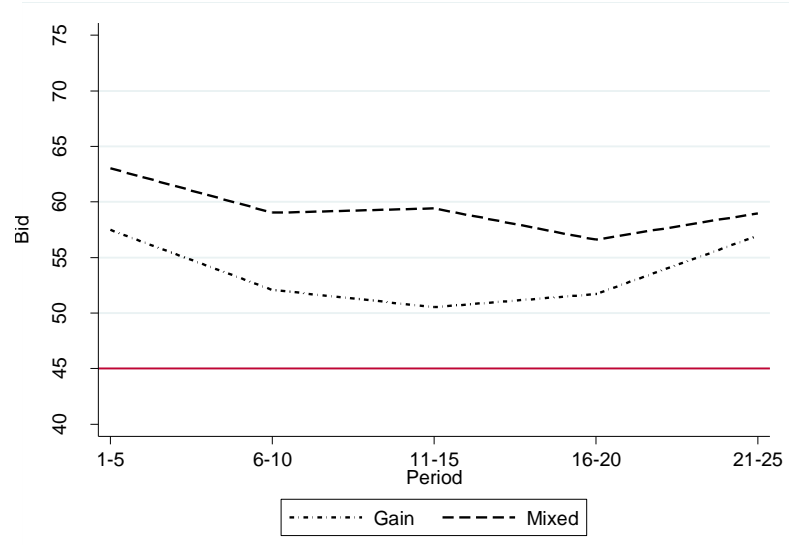

Table 4. Descriptive statistics of bids

\begin{tabular}{lccc}
\hline & Obs. & Mean & St Dev \\
\hline Loss & 22 & 71.901 & 17.858 \\
Mixed (holder) & 44 & 65.914 & 26.340 \\
Mixed (non-holder) & 44 & 59.409 & 23.680 \\
Gain & 22 & 53.747 & 19.426 \\
\hline
\end{tabular}

Both Figure 3 and Table 4 illustrate that there is a ranking of bids as follows: Loss > Mixed (property rights holder) $>$ Mixed (property rights non-holder) $>$ Gain. This is indicative of support for Hypothesis 2, that the property rights holders bid more than the non-holders within the Mixed treatment. Furthermore, it suggests partial support for Hypotheses 3: bids in the Loss treatment are greater than bids of property rights holders in the Mixed treatment. But bids in the Gain treatment are not greater than the bids of property rights non-holders in the Mixed treatment. 
However, a two-sided Wilcoxon test shows no difference in bids between those who have property rights in Mixed versus those in Loss: $\mathrm{z}=1.360 ; \mathrm{p}=0.174$. This constitutes a rejection of Hypothesis 3. Similarly, a two-sided Wilcoxon tests shows no significant difference between who don't have property rights in Mixed vs. those in Gain: $z=-0.680 ; p=$ 0.496 . This is characterized by Result 2 .

Result 2: There is no significant difference between the bids of the holders of property rights in the Loss and in the Mixed treatment, as well as between the bids of the non-holders of property rights in the Gain and in the Mixed treatment.

Finally, to distinguish between the bids of the holders and non-holders of property rights within the Mixed treatments (note that these observations are not independent) we implement a $t$-test that confirms treatment difference in bids $(t=1.836, \mathrm{p}=0.074)$ supporting Hypothesis 2.

Note, however, the tests employed so far have been very conservative, given that those cannot incorporate the individual-specific or demographic effects, nor can those account for temporal effects. Most importantly, those cannot incorporate the cardinal information in the data. To incorporate all of these features, and to test robustness of the results above, we run a series of random effects panel regressions as reported in Table 5.

The dependent variable is the bid by an individual subject in a period. We cluster standard errors at the subject-pair level and at the session level and run the regressions (a) for the whole data, (b) for only Gain treatment and Loss treatment data, and (c) separately for the Mixed treatment data. We are interested in the treatment effect and hence include two treatment dummies (keeping Gain as baseline) for the whole data and a dummy for the loss treatment in the Gain + Loss data. Furthermore, for the Mixed treatment we include a dummy for the holder of the property rights. A set of controls are also included. The demographic controls consist of a 'risky behavior' dummy (choosing more risky options 4-6 over less risky options 1-3 in the risk test), age, gender (female $=1$ ), and experience in participating in economics experiments. The strategic controls are the lag of a player's own bid, lag of the rival's bid, a dummy for whether the player won in the last period, and a time trend. Our variables of interest are the treatment dummies and dummy for holder of property rights in the Mixed treatment. 
Table 5. Random effects regression results

\begin{tabular}{|c|c|c|c|c|c|c|}
\hline Dep. var: Bid & All & All & Gain-Loss & Gain-Loss & Mixed & Mixed \\
\hline Lag bid & $\begin{array}{l}0.485^{* * *} \\
(0.032)\end{array}$ & $\begin{array}{l}0.474^{* * *} \\
(0.030)\end{array}$ & $\begin{array}{l}0.453^{* * *} \\
(0.038)\end{array}$ & $\begin{array}{l}0.444^{* * *} \\
(0.038)\end{array}$ & $\begin{array}{l}0.504^{* * *} \\
(0.048)\end{array}$ & $\begin{array}{c}0.480^{* * *} \\
(0.044)\end{array}$ \\
\hline Lag win & $\begin{array}{c}-4.624^{* * *} \\
(1.044)\end{array}$ & $\begin{array}{l}-4.461^{* * *} \\
(1.045)\end{array}$ & $\begin{array}{c}-3.247^{* * *} \\
(1.192)\end{array}$ & $\begin{array}{c}-3.150^{* * *} \\
(1.189)\end{array}$ & $\begin{array}{l}-6.215^{* * *} \\
(1.702)\end{array}$ & $\begin{array}{l}-5.814^{* * *} \\
(1.702)\end{array}$ \\
\hline Lag other bid & $\begin{array}{l}0.174^{* * *} \\
(0.023)\end{array}$ & $\begin{array}{l}0.170^{* * *} \\
(0.023)\end{array}$ & $\begin{array}{l}0.215^{* * *} \\
(0.026)\end{array}$ & $\begin{array}{l}0.211^{* * *} \\
(0.027)\end{array}$ & $\begin{array}{l}0.147^{* * *} \\
(0.033)\end{array}$ & $\begin{array}{l}0.143^{* * *} \\
(0.031)\end{array}$ \\
\hline $\begin{array}{l}\text { Loss treatment } \\
\text { dummy }\end{array}$ & $\begin{array}{l}6.457^{* * * *} \\
(2.095)\end{array}$ & $\begin{array}{l}7.079^{* * *} \\
(2.075)\end{array}$ & $\begin{array}{l}6.275^{* * *} \\
(2.195)\end{array}$ & $\begin{array}{l}6.526^{* * *} \\
(2.184)\end{array}$ & & \\
\hline $\begin{array}{l}\text { Mixed treatment } \\
\text { dummy }\end{array}$ & $\begin{array}{c}3.042 \\
(1.919)\end{array}$ & $\begin{array}{l}4.068^{* *} \\
(1.855)\end{array}$ & & & & \\
\hline $\begin{array}{l}\text { Property } \\
\text { rights holder }\end{array}$ & & & & & $\begin{array}{l}4.657^{*} \\
(2.409)\end{array}$ & $\begin{array}{l}6.689^{* *} \\
(2.625)\end{array}$ \\
\hline Period & $\begin{array}{l}-0.009 \\
(0.075)\end{array}$ & $\begin{array}{l}-0.013 \\
(0.078)\end{array}$ & $\begin{array}{c}0.010 \\
(0.124)\end{array}$ & $\begin{array}{c}0.008 \\
(0.127)\end{array}$ & $\begin{array}{l}-0.031 \\
(0.084)\end{array}$ & $\begin{array}{l}-0.040 \\
(0.088)\end{array}$ \\
\hline Risk dummy & & $\begin{array}{c}-5.363^{* * *} \\
(1.535)\end{array}$ & & $\begin{array}{l}-3.299^{*} \\
(1.854)\end{array}$ & & $\begin{array}{c}-6.868^{* * *} \\
(2.413)\end{array}$ \\
\hline Age $\geq 21$ & & $\begin{array}{l}-2.796^{*} \\
(1.532)\end{array}$ & & $\begin{array}{l}-0.415 \\
(1.917)\end{array}$ & & $\begin{array}{l}-5.448^{* *} \\
(2.467)\end{array}$ \\
\hline Female & & $\begin{array}{l}-0.721 \\
(1.571)\end{array}$ & & $\begin{array}{c}0.976 \\
(2.056)\end{array}$ & & $\begin{array}{l}-2.750 \\
(2.586)\end{array}$ \\
\hline $\begin{array}{l}\text { Experience in } \\
\text { Experiment }\end{array}$ & & $\begin{array}{c}0.178 \\
(0.109)\end{array}$ & & $\begin{array}{l}0.196^{*} \\
(0.110)\end{array}$ & & $\begin{array}{l}-0.156 \\
(0.474)\end{array}$ \\
\hline Constant & $\begin{array}{l}20.80^{* * *} \\
(2.676)\end{array}$ & $\begin{array}{l}24.61^{* * *} \\
(2.963)\end{array}$ & $\begin{array}{l}19.39^{* * *} \\
(3.225)\end{array}$ & $\begin{array}{l}20.10^{* * *} \\
(3.696)\end{array}$ & $\begin{array}{l}23.05^{* * *} \\
(4.371)\end{array}$ & $\begin{array}{l}31.79^{* * * *} \\
(4.879)\end{array}$ \\
\hline Observations & 4224 & 4224 & 2112 & 2112 & 2112 & 2112 \\
\hline
\end{tabular}

Note: Numbers in parentheses are SEs clustered at subject-pair and session level; *, **, and ** denote significance at $10 \%, 5 \%$ and $1 \%$ levels.

The regressions provide several interesting results. First, these reiterate Result 1 and Result 2. Both in the combined regression as well as in the regression comparing only the Loss and the Gain treatments, the coefficient for the Loss treatment dummy is positive and significant at the $1 \%$ level. Furthermore, unlike with the non-parametric tests, the dummy for 
the Mixed treatment is also positive and significant. Hence, these provide stronger support for Hypothesis $1 .{ }^{4}$ Finally, the dummy for property rights holder in the Mixed treatment is positive and significant - indicating that the bids by the property rights holders are higher than the nonholders within the Mixed treatment. These (along with the $t$-test result described earlier) provide formal support for loss aversion and for Hypothesis 2, and lead to Result 3:

Result 3: The bids entered by the holders of property rights are greater than the bids entered by the non-holders of property rights within the Mixed treatment.

\section{A behavioral explanation for the lack of significant differences in ranking}

In the previous section we showed that both between the Loss and the Gain treatments as well as within the Mixed treatment a holder of property rights enters higher bids than a nonholder. This is explained by a theoretical model with loss aversion. However, some other predictions regarding the ranking (e.g., $\overline{b_{M}}>b_{G}$ and $b_{G}>b_{M G}$ ) are not supported by the experimental data and we cannot reject $\overline{b_{M}}=b_{G}$ and $b_{G}=b_{M G}$. Although the model with loss aversion fulfills the main objective of predicting treatment effects, it does not include social preferences of the subjects. Here we argue that social preferences such as inequality aversion may explain the divergence between these hypotheses and empirical findings; i.e., a model with social preference may explain why we do not find such clear ranking of bids in our data.

We introduce a linear model of inequality aversion of Fehr and Schmidt (1999) as applied by Herrman and Orzen (2008) to contests. The model postulates that a subject might dislike disadvantageous inequity in payoffs, i.e., dislikes being behind others. Further, he might dislike it when the rival is disadvantaged; or might prefer such inequality if he is spiteful. Then the utility function with social preferences for player $i$ is:

$U_{i}\left(b_{i}, b_{j}\right)=u_{i}-\alpha \max \left(u_{j}-u_{i}, 0\right)-\beta \max \left(u_{i}-u_{j}, 0\right)$

where $u_{i}$ and $u_{j}$ are the players' utility without social preference (but with loss aversion), and $\alpha \geq 0$ and $\beta \leq 1$ are the disadvantageous and advantageous inequity aversion parameters (with more weight to disadvantageous inequity, i.e., $\alpha \geq \beta$, and a negative $\beta$ captures spite).

The utility function without social preference but with loss aversion for a player with no property rights is given by Eq. 9, whereas the utility with property rights is given by Eq. 10 . Including those in Eq. 12 and solving, it is easy to show that the equilibrium bid in the Loss frame is higher than the same in the Gain frame. This is summarized in the proposition below.

\footnotetext{
${ }^{4}$ The coefficients for the controls have the usual signs and significance levels (see, e.g., Dechenaux et al., 2015).
} 
Proposition 1. Equilibrium bid with social preference in the Gain frame is $b_{G}^{*}=\frac{V(1+\alpha-\beta)}{2(2+\alpha-\beta)}$ and in the Loss frame is $b_{L}^{*}=\frac{\lambda V(1+\alpha-\beta)}{2(2+\alpha-\beta)}$.

Proof: See Appendix I-A.

Interestingly, Proposition 1 shows that since $\lambda>1, b_{L}^{*}>b_{G}^{*}$ : i.e., bids are higher in the Loss treatment than in the Gain treatment - even after accounting for the social preferences.

It is, however, not easy to find a closed form solution for the Mixed frame, and no specific hypotheses relating to the Mixed treatment can be stated. This is since the ranking may change depending on the values attached to the inequity aversion parameters. The most we can obtain are the best response functions. These are presented in the next proposition.

Proposition 2. If player $i$ is the holder of property rights and player $j$ is not, then the equilibrium bid with social preference in the Mixed frame is obtained by solving the best response functions:

$V \frac{b_{j}}{\left(b_{i}+b_{j}\right)^{2}}-(1-\lambda) V \frac{b_{j}}{\left(b_{i}+b_{j}\right)^{2}}-1+\alpha \lambda V \frac{b_{j}}{\left(b_{i}+b_{j}\right)^{2}}-\alpha \frac{b_{j}^{2}}{\left(b_{i}+b_{j}\right)^{2}}-\alpha \frac{b_{j}^{2}}{\left(b_{i}+b_{j}\right)^{2}}-\beta V \frac{b_{j}}{\left(b_{i}+b_{j}\right)^{2}}-$ $\beta \frac{b_{j}^{2}}{\left(b_{i}+b_{j}\right)^{2}}+\beta \frac{2 b_{i} b_{j}+b_{i}^{2}}{\left(b_{i}+b_{j}\right)^{2}}=0$

$V \frac{b_{i}}{\left(b_{i}+b_{j}\right)^{2}}-1+\alpha V \frac{b_{i}}{\left(b_{i}+b_{j}\right)^{2}}-\alpha \frac{b_{i}^{2}}{\left(b_{i}+b_{j}\right)^{2}}-\alpha \frac{b_{i}^{2}}{\left(b_{i}+b_{j}\right)^{2}}-\beta \lambda V \frac{b_{i}}{\left(b_{i}+b_{j}\right)^{2}}-\beta \frac{b_{i}^{2}}{\left(b_{i}+b_{j}\right)^{2}}+$ $\beta \frac{2 b_{i} b_{j}+b_{j}^{2}}{\left(b_{i}+b_{j}\right)^{2}}=0$.

Proof: See Appendix I-B.

We now show that depending on the values of the social preference parameters and the loss aversion parameter, it is possible that $\overline{b_{M}}>b_{G}$ or $\overline{b_{M}}<b_{G}$. As a numerical example, consider $V=180, \lambda=2, \alpha=0.5$. Now, when $\beta=0.3$ then $\overline{b_{M}}=41.882<49.091=b_{G}$; but when $\beta=-0.3$, then $\overline{b_{M}}=79.781>57.857=b_{G}$. Similarly for some parameter ranges it may be that $b_{G}>b_{M G}$ but for some other parameter ranges $b_{G}<b_{M G}$.

To provide a visual representation of this fact and to show how these opposite results occur over parameter ranges, we run simulations of individual bids in the three treatments for $V=180, \lambda=2, \alpha \in[0,1], \beta \in[-0.5,0.5]$ and $\alpha \geq \beta$. First, unsurprisingly, the simulations support Hypothesis 2: the equilibrium bid by the property rights holder in the Mixed treatment is higher than non-holder in the same treatment, i.e., $b_{M L}>b_{M G}$. 
Next, we test whether Hypothesis 1, which predicts higher average bids in the Mixed treatment compared than in the Gain treatment $\left(\overline{b_{M}}>b_{G}\right)$, holds. The result is shown in Figure 4 and the details of the simulation procedures are reported in Appendix I-C. The equilibrium bid in the Mixed treatment is greater (lower) than the bid in the Gain treatment in the light (dark) grey area (white area shows $\alpha<\beta$ ). Hence, with a mix of subjects some of whom belong to the light grey area whereas some other belong to the dark grey area, then the overall empirical result may become unclear; explaining insignificant difference between the bid levels.

Figure 4. Simulated bids in the Mixed treatment versus in the Gain treatment

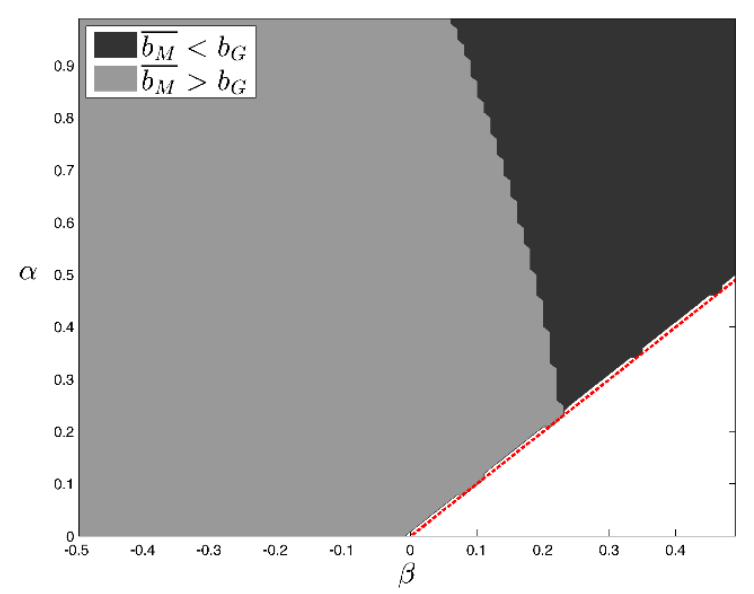

We further run simulations with the same parametric restrictions for the non-holders of property rights in the Mixed and Gain treatments. Observe from Figure 5 that the equilibrium bids by such players in the Mixed treatment are greater (lower) than the bid in the Gain treatment in the light (dark) grey area. In specific, for low $\alpha$ values when there is spite $(\beta<0)$ the theoretical prediction from Hypothesis $3\left(b_{M G}<b_{G}\right)$ may be reversed. Hence, when the subject pool has both type of individuals, then we may not be able to reject that $b_{M G}=b_{G}$.

Figure 5. Simulated bids by non-holders in the Mixed treatment vs. in the Gain treatment

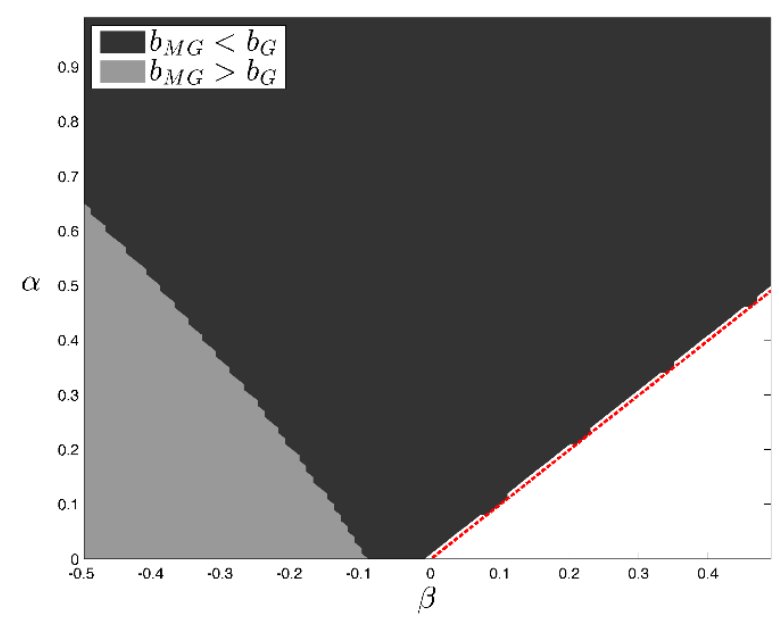




\section{Discussion}

We analyze the effects of property rights and the resulting loss aversion on behavior in contests. We implement a novel experimental design that changes the property rights only through framing. The standard theoretical models of expected utility (Tullock, 1980) or loss aversion (Cornes and Hartely, 2012) predict no difference in bids between treatments, whereas a loss aversion model with salient property rights - that we introduce - provides a clear ranking of equilibrium bids across treatments. Furthermore, whereas existing contest experiments involving loss aversion show a lower bid as a result of loss aversion, we predict the opposite. In our experiment, bids in the Loss frame are significantly higher than bids in the Gain frame both in the 'pure' as well as in the Mixed treatments - confirming our theoretical predictions. Some further rankings of bids are not statistically significant, and a behavioral model that accounts for differences in social preferences can explain this lack of significant differences.

These results have several interesting implications. First, the existing literature cannot explain the real-life phenomenon that a property rights holder expends higher effort than a nonholder (e.g. the Kauravas expended more resources than the Pandavas in the Indian epic Mahabharata, or a host wasp spends more effort than an invader wasp, or Israel - ceteris paribus - spends more on military in Golan Heights than Syria). We, in contrast, show that the effect of property rights and loss aversion is very robust: property rights and the resulting loss aversion result in higher bids. Both our theoretical and empirical results, hence, provide a micro-founded explanation of such field observations from biology, litigation, and conflict literatures. Second, this is the first experiment, to our knowledge, that employs framing in understanding behavior in a contest setting. There is a recent strand of literature that investigates the effects of experimental design (see Chowdhury et al. (2014) for an example and literature) on contest outcomes. The current study contributes also to this area. Third, and relating to the second point above, these results provide new insights for both contest design and policy. For example, since it is possible to manipulate bids in contests by simply changing the frame, it may be useful to introduce such framing effects as 'nudges' in organizations and tournaments. Finally, we believe that the current results will provide guidance for future research in the areas of both contest theory and behavioral conflict literature. 


\section{References}

Alchian, A. A., \& Demsetz, H. (1973). The property right paradigm. The Journal of Economic History, 33(01), 16-27.

Barzel, Y. (1997). Economic analysis of property rights. Cambridge University Press.

Chowdhury, S. M., \& Sheremeta, R. M. (2011). A generalized Tullock contest. Public Choice, 147(3), 413-420.

Chowdhury, S. M., Sheremeta, R. M., \& Turocy, T. L. (2014). Overbidding and overspreading in rent-seeking experiments: Cost structure and prize allocation rules. Games and Economic Behavior, 87, 224-238.

Colombatto, E. (2004). The Elgar companion to the economics of property rights. Edward Elgar.

Cornes, R., \& Hartley, R. (2003). Loss aversion and the Tullock paradox, University of Nottingham Economics Discussion Paper No. 03/17.

Cornes, R., \& Hartley, R. (2012). Loss aversion in contests. University of Manchester Economics Discussion Paper No. 1204.

Dechenaux, E., Kovenock, D., \& Sheremeta, R. M. (2015). A survey of experimental research on contests, all-pay auctions and tournaments. Experimental Economics, 18(4), 609669.

Dutcher, E. G., Balafoutas, L., Lindner, F., Ryvkin, D., \& Sutter, M. (2015). Strive to be first or avoid being last: An experiment on relative performance incentives. Games and Economic Behavior, 94, 39-56.

Eckel, C.C., \& Grossman, P.J. (2008). Forecasting Risk Attitudes: An Experimental Study

Using Actual and Forecast Gamble Choices, Journal of Economic Behavior \& Organization, 68 (1), 1-17.

Eisenkopf, G., \& Teyssier, S. (2013). Envy and loss aversion in tournaments. Journal of Economic Psychology, 34, 240-255.

Ernst, C., \& Thöni, C. (2013). Bimodal bidding in experimental all-pay auctions. Games, 4, 608-623.

Falk, A., Fehr, E., \& Huffman, D. (2008). The power and limits of tournament incentives. Work in progress.

Fehr, E., \& Schmidt, K. M. (1999). A theory of fairness, competition, and cooperation. Quarterly Journal of Economics, 817-868.

Fischbacher, U. (2007). z-Tree: Zurich Toolbox for Ready-made Economic Experiments. Experimental Economics, 10 (2), 171-178.

Gill, D., \& Prowse, V. (2012). A structural analysis of disappointment aversion in a real effort competition. American Economic Review, 102, 469-503.

Gill, D., \& Stone, R. (2010). Fairness and desert in tournaments. Games and Economic Behavior, 69(2), 346-364.

Greiner, B. (2015). Subject Pool Recruitment Procedures: Organizing Experiments with ORSEE. Journal of the Economic Science Association, 1(1), 114-125.

Hafer, C. (2006). On the origins of property rights: Conflict and production in the state of nature. The Review of Economic Studies, 73(1), 119-143.

Herrmann, B., \& Orzen, H. (2008). The appearance of homo rivalis: Social preferences and the nature of rent seeking (No. 2008-10). CeDEx discussion paper series.

Hoffman, E., McCabe, K., Shachat, K., \& Smith, V. (1994). Preferences, property rights, and anonymity in bargaining games. Games and Economic Behavior, 7(3), 346-380.

Humphries, E. L., Hebblethwaite, A. J., Batchelor, T. P., \& Hardy, I. C. (2006). The importance of valuing resources: host weight and contender age as determinants of parasitoid wasp contest outcomes. Animal Behaviour, 72(4), 891-898. 
Kahneman, D., \& Tversky, A. (1979). Prospect theory: An analysis of decision under risk. Econometrica, 47(2), 263-291.

Kahneman, D., Knetsch, J. L., \& Thaler, R. H. (1991). Anomalies: The endowment effect, loss aversion, and status quo bias. The Journal of Economic Perspectives, 5(1), 193-206.

Kimbrough, E.O., \& Sheremeta, R.M. (2014). Why can't we be friends? Entitlements and the costs of conflict. Journal of Peace Research, 51, 487-500.

Kolmar, M. (2008). Perfectly secure property rights and production inefficiencies in Tullock contests. Southern Economic Journal, 75(2), 441-456.

Kong, X. (2008). Loss aversion and rent-seeking: An experimental study (No. 2008-13). CeDEx discussion paper series.

Lee, J. (2004). Prize and risk-taking strategy in tournaments: evidence from professional poker players. IZA DP No. 1345.

Levy, J. S. (1996). Loss aversion, framing, and bargaining: The implications of prospect theory for international conflict. International Political Science Review, 17(2), 179-195.

Miranda, M. J., \& Fackler, P. L. (2004). Applied computational economics and finance. MIT press.

Morgan, J., \& Sisak, D. (2016). Aspiring to succeed: A model of entrepreneurship and fear of failure. Journal of Business Venturing, 31(1), 1-21.

Petersen, G., \& Hardy, I. C. (1996). The importance of being larger: parasitoid intruder-owner contests and their implications for clutch size. Animal Behaviour, 51(6), 1363-1373.

Price, C.R., \& Sheremeta, R.M. (2015). Endowment origin, demographic effects and individual preferences in contests. Journal of Economics and Management Strategy, 24, 597-619.

Sheremeta, R. M. (2013). Overbidding and heterogeneous behavior in contest experiments. Journal of Economic Surveys, 27(3), 491-514.

Sheremeta, R.M. (2016). Impulsive behavior in competition: Testing theories of overbidding in rent-seeking contests. Working Paper.

Shupp, R., Sheremeta, R.M., Schmidt, D., \& Walker, J. (2013). Resource allocation contests: Experimental evidence. Journal of Economic Psychology, 39, 257-267.

Skaperdas, S. (1992). Cooperation, conflict, and power in the absence of property rights. The American Economic Review, 82(4), 720-739.

Smith, J. D. (Ed.). (2009). The Mahabharata. Penguin Classics.

Stockermans, B. C., \& Hardy, I. C. (2013). Subjective and objective components of resource value additively increase aggression in parasitoid contests. Biology Letters, 9(4), 20130391.

Stokkebo, S., \& Hardy, I. C. (2000). The importance of being gravid: egg load and contest outcome in a parasitoid wasp. Animal Behaviour, 59(6), 1111-1118.

Szidarovszky, F., \& Okuguchi, K. (1997). On the Existence and Uniqueness of Pure Nash Equilibrium in Rent-Seeking Games. Games and Economic Behavior, 18(1), 135-140.

Tullock, Gordon (1980). Efficient Rent Seeking. In J.M. Buchanan, R.D. Tollison, and G. Tullock, (Eds.), Toward a Theory of the Rent-seeking Society. Texas A\&M University Press, College Station, TX, 97-112.

Tversky, A., \& Kahneman, D. (1991). Loss aversion in riskless choice: A reference-dependent model. The Quarterly Journal of Economics, 106(4), 1039-1061.

Zamir, E., \& Ritov, I. (2012). Loss aversion, omission bias, and the burden of proof in civil litigation. The Journal of Legal Studies, 41(1), 165-207. 


\section{Appendix I: Proofs of the Propositions and Simulation Details}

\section{A. Proof of Proposition 1}

From Eq. 12, the utility function with social preference for player $i$ is:

$$
U_{i}\left(b_{i}, b_{j}\right)=u_{i}-\alpha \max \left(u_{j}-u_{i}, 0\right)-\beta \max \left(u_{i}-u_{j}, 0\right)
$$

For the Gain treatment, we impose Eq. 9 and after some manipulation the utility under social preference becomes -

$U_{i}\left(b_{i}, b_{j}\right)=\frac{b_{i}}{b_{i}+b_{j}} V+\left(E-b_{i}\right)-\alpha \frac{b_{j}}{b_{i}+b_{j}}\left[V+b_{i}-b_{j}\right]-\beta \frac{b_{i}}{b_{i}+b_{j}}\left[V+b_{j}-b_{i}\right]$

Calculations for obtaining the equilibrium bid for the Gain treatment can be obtained directly from Herrmann and Orzen (2008, pp. 37-39). This leads to:

$$
b_{G}^{*}=\frac{V(1+\alpha-\beta)}{2(2+\alpha-\beta)}
$$

For the Loss treatment, we impose Eq. 10 and after some manipulation the utility under social preference becomes -

$$
\begin{aligned}
& U_{i}\left(b_{i}, b_{j}\right)=\frac{b_{i}}{b_{i}+b_{j}} V+\frac{b_{j}}{b_{i}+b_{j}}(1-\lambda) V+\left(E-b_{i}\right)-\alpha \frac{b_{j}}{b_{i}+b_{j}}\left[\lambda V+b_{i}-b_{j}\right]- \\
& \beta \frac{b_{i}}{b_{i}+b_{j}}\left[\lambda V+b_{j}-b_{i}\right] \\
& \frac{\partial U_{i}\left(b_{i}, b_{j}\right)}{\partial b_{i}}=V \frac{b_{j}}{\left(b_{i}+b_{j}\right)^{2}}-(1-\lambda) V \frac{b_{j}}{\left(b_{i}+b_{j}\right)^{2}}-1+\alpha \lambda V \frac{b_{j}}{\left(b_{i}+b_{j}\right)^{2}}-\alpha \frac{b_{j}^{2}}{\left(b_{i}+b_{j}\right)^{2}} \\
& \quad-\alpha \frac{b_{j}^{2}}{\left(b_{i}+b_{j}\right)^{2}}-\beta \lambda V \frac{b_{j}}{\left(b_{i}+b_{j}\right)^{2}}-\beta \frac{b_{j}^{2}}{\left(b_{i}+b_{j}\right)^{2}}+\beta \frac{2 b_{i} b_{j}+b_{i}^{2}}{\left(b_{i}+b_{j}\right)^{2}}
\end{aligned}
$$

Symmetry implies $b_{i}=b_{j}=b^{*}$ imposing this in $\frac{\partial U_{i}\left(b_{i}, b_{j}\right)}{\partial b_{i}}=0$ returns -

$$
\begin{gathered}
V \frac{1}{4 b^{*}}-(1-\lambda) V \frac{1}{4 b^{*}}-1+\alpha \lambda V \frac{1}{4 b^{*}}-\alpha \frac{1}{4}-\alpha \frac{1}{4}-\beta \lambda V \frac{1}{4 b^{*}}-\beta \frac{1}{4}+\beta \frac{3}{4}=0 \\
\frac{V}{2 b^{*}}-\frac{(1-\lambda) V}{2 b^{*}}+\frac{\alpha \lambda V}{2 b^{*}}-\frac{\beta \lambda V}{2 b^{*}}=(2+\alpha-\beta) \\
b_{L}^{*}=\frac{\lambda V(1+\alpha-\beta)}{2(2+\alpha-\beta)} .
\end{gathered}
$$




\section{B. Proof of Proposition 2}

For the Mixed treatment, let player $i$ has property rights and player $j$ doesn't, then following the same procedure as in Proposition 1 we obtain the utility under social preference for the non-holder of the property rights as -

$U_{i}\left(b_{i}, b_{j}\right)=\frac{b_{i}}{b_{i}+b_{j}} V+\frac{b_{j}}{b_{i}+b_{j}}(1-\lambda) V+\left(E-b_{i}\right)-\alpha \frac{b_{j}}{b_{i}+b_{j}}\left[\lambda V+b_{i}-b_{j}\right]-$

$\beta \frac{b_{i}}{b_{i}+b_{j}}\left[V+b_{j}-b_{i}\right]$

FOC: $\frac{\partial U_{i}\left(b_{i}, b_{j}\right)}{\partial b_{i}}=0$ implies

$V \frac{b_{j}}{\left(b_{i}+b_{j}\right)^{2}}-(1-\lambda) V \frac{b_{j}}{\left(b_{i}+b_{j}\right)^{2}}-1+\alpha \lambda V \frac{b_{j}}{\left(b_{i}+b_{j}\right)^{2}}-\alpha \frac{b_{j}^{2}}{\left(b_{i}+b_{j}\right)^{2}}-\alpha \frac{b_{j}^{2}}{\left(b_{i}+b_{j}\right)^{2}}-\beta V \frac{b_{j}}{\left(b_{i}+b_{j}\right)^{2}}-$ $\beta \frac{b_{j}^{2}}{\left(b_{i}+b_{j}\right)^{2}}+\beta \frac{2 b_{i} b_{j}+b_{i}^{2}}{\left(b_{i}+b_{j}\right)^{2}}=0$

Similarly, the utility under social preference for the holder of the property rights is -

$U_{j}\left(b_{i}, b_{j}\right)=\frac{b_{j}}{b_{i}+b_{j}} V+\left(E-b_{j}\right)-\alpha \frac{b_{i}}{b_{i}+b_{j}}\left[V+b_{j}-b_{i}\right]-\beta \frac{b_{j}}{b_{i}+b_{j}}\left[\lambda V+b_{i}-b_{j}\right]$

FOC: $\frac{\partial U_{j}\left(b_{i}, b_{j}\right)}{\partial b_{j}}=0$ implies

$V \frac{b_{i}}{\left(b_{i}+b_{j}\right)^{2}}-1+\alpha V \frac{b_{i}}{\left(b_{i}+b_{j}\right)^{2}}-\alpha \frac{b_{i}^{2}}{\left(b_{i}+b_{j}\right)^{2}}-\alpha \frac{b_{i}^{2}}{\left(b_{i}+b_{j}\right)^{2}}-\beta \lambda V \frac{b_{i}}{\left(b_{i}+b_{j}\right)^{2}}-\beta \frac{b_{i}^{2}}{\left(b_{i}+b_{j}\right)^{2}}+$ $\beta \frac{2 b_{i} b_{j}+b_{j}^{2}}{\left(b_{i}+b_{j}\right)^{2}}=0$

\section{Details of the simulation}

The simulations are run using Matlab. The details of the procedures are described below.

The FOCs are defined as FOC: $\mathbb{R}^{2} \mapsto \mathbb{R}^{2}$, more specifically

$$
\operatorname{FOC}\left(b_{i}, b_{j}\right)=\left[\begin{array}{l}
\frac{\partial u_{i}\left(b_{i}, b_{j}\right)}{\partial b_{i}} \\
\frac{\partial u_{j}\left(b_{i}, b_{j}\right)}{\partial b_{j}}
\end{array}\right]
$$


Thus, strictly speaking, this function only returns the derivative of both utility functions at a certain combination of bid levels.

We iterate on this function using a multivariate version of the Newton-Raphson algorithm with convergence criteria $\varepsilon=\delta=10^{-6}$ and a maximum of 100 iterations. ${ }^{5}$ The initial vector of bids comes from two random draws from uniform $[0,1]$.

Since the results seem to vary marginally with the draw of the initial vector, for each parameter constellation we drew 50 initial vectors, solved and only took the average of all those solutions into account if the sum of squares of these 50 draws was less than 0.01 .

This script was used in the following algorithm: ${ }^{6}$

1. Set $\alpha=-0.05, \beta=-0.55, \lambda=2, V=180$.

2. Increase $\alpha$ by 0.05 .

3. Increase $\beta$ by 0.05 .

4. Compute equilibrium bids (for all 4 frames) and store together with $\alpha$ and $\beta$.

5. If $\beta<0.5$, then go to Step 3, otherwise set $\beta=-0.55$ and go to the next step.

6. If $\alpha<1$, then go to Step 2, otherwise stop.

The matrix that contains all saved data from step 4 is cleaned from all non-convergent cases and infinite solutions. It is the resulting matrix with which we created the graphs.

The Matlab codes are available from the corresponding author by request.

\footnotetext{
${ }^{5}$ Where $\varepsilon$ is the maximal distance between two iteration steps on bid levels we allow and $\delta$ is the maximum value the derivatives can have at a solution. See e.g. Miranda and Fackler (2004) for a detailed description.

${ }^{6}$ One can estimate $\lambda$ from the Gain and the Loss treatments and the estimated value is $\lambda=\sim 1.35$. Although we have implemented $\lambda=2$ for easier visual representation in our simulation, qualitative results from the simulation remains the same even when we make $\lambda=1.35$.
} 


\section{Appendix II: Instructions}

\section{GENERAL INSTRUCTIONS}

This is an experiment in the economics of decision making. This experiment consists of two unrelated parts. Instructions for the first part are given next and the instructions for the second part will be provided after the first part of the experiment is finished.

The instructions are simple. If you follow them closely and make appropriate decisions, you can earn an appreciable amount of money.

It is very important that you remain silent and do not look at other people's work. If you have any questions, or need assistance of any kind, please raise your hand and an experimenter will come to you. If you talk, laugh, exclaim out loud, etc., you will be asked to leave and you will not be paid. We expect and appreciate your cooperation.

Experimental Currency is used in the experiment and your decisions and earnings will be recorded in tokens. At the end of today's experiment, you will be paid in private and in cash. Tokens earned from both parts of the experiment will be converted to Pound Sterling at a rate of:

$\underline{1}$ token to $\underline{\mathbf{3}}$ Pence $(£ 0.03)$. 


\section{INSTRUCTIONS - PART 1}

In this task, you will be asked to choose from six different gambles (as shown below). Each circle represents a different gamble from which you must choose the one that you prefer. Each circle is divided in half, with the number of tokens that the gamble will give you in each circle.
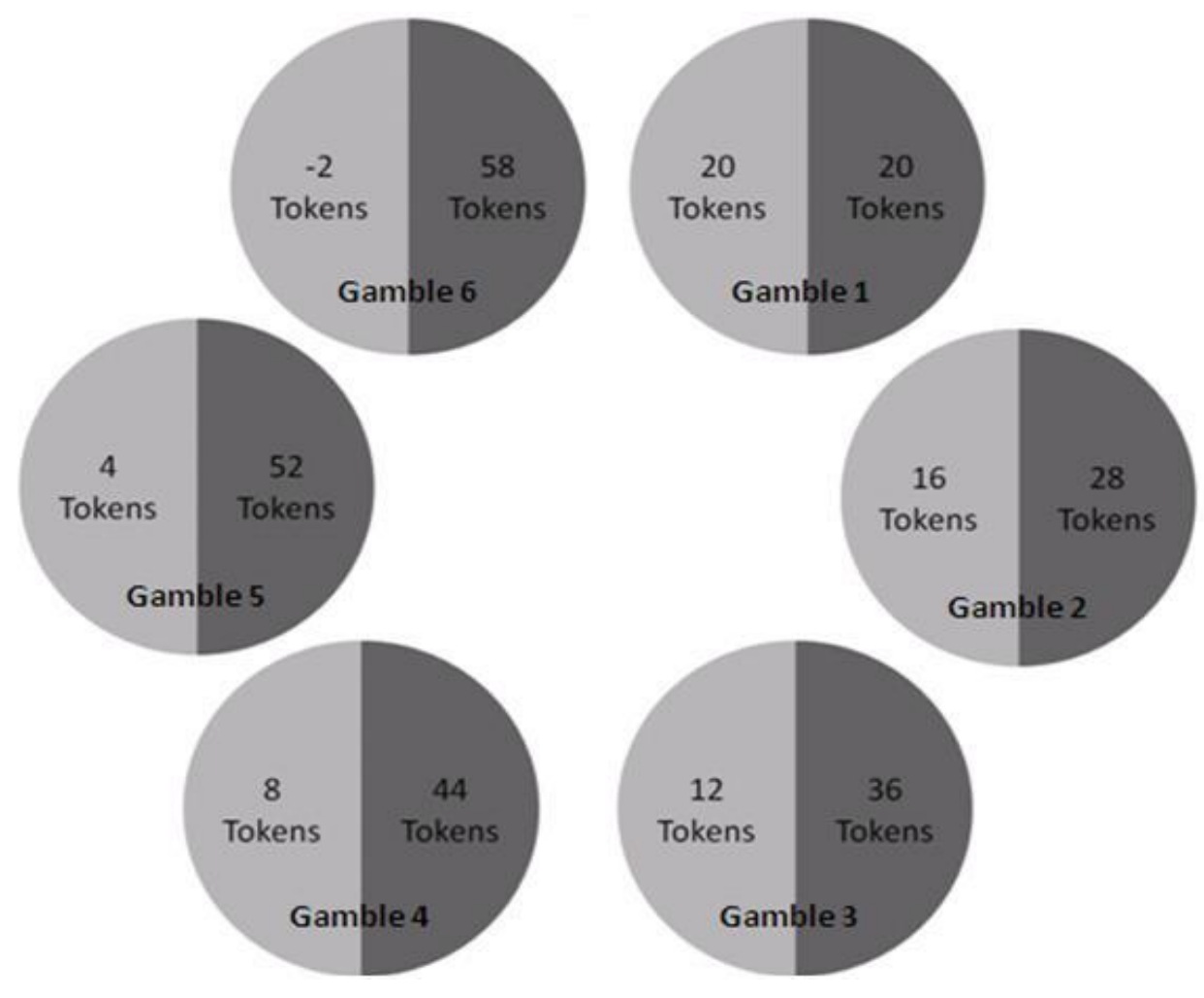

Your payment for this task will be determined at the end of today's experiment. A volunteer will come to the front of the room and toss a coin. If the outcome is heads, you will receive the number of tokens in the light grey area of the circle you have chosen. Alternatively, if the outcome is tails, you will receive the number of tokens shown in the dark grey area of the circle you have chosen. Note that no matter which gamble you pick, each outcome has a $50 \%$ chance of occurring.

Please select the gamble of your choice by clicking one of the "Check here" buttons that will appear on each circle in the picture Once you have made your choice, please click the "Confirm" button at the bottom of the screen.

For your record, also tick the gamble you have chosen in the above picture.

Once everyone has made their decision, this task will end and we will move on to Part 2 of the experiment. Your payment for this task will be decided at the end of today's experiment. 


\section{INSTRUCTIONS - GAIN}

\section{YOUR DECISION}

This part of the experiment consists of $\mathbf{2 5}$ decision-making periods. At the beginning, you will be randomly and anonymously placed into a group of $\mathbf{2}$ participants. The composition of your group will remain the same for all 25 periods. You will not know who your group member is at any time.

Each period you will receive an initial endowment of $\mathbf{1 8 0}$ tokens. Each period, you may bid for a reward of 180 tokens. You may bid any number between $\mathbf{0}$ and $\mathbf{1 8 0}$ (including 0.1 decimal points). An example of your decision screen is shown below.

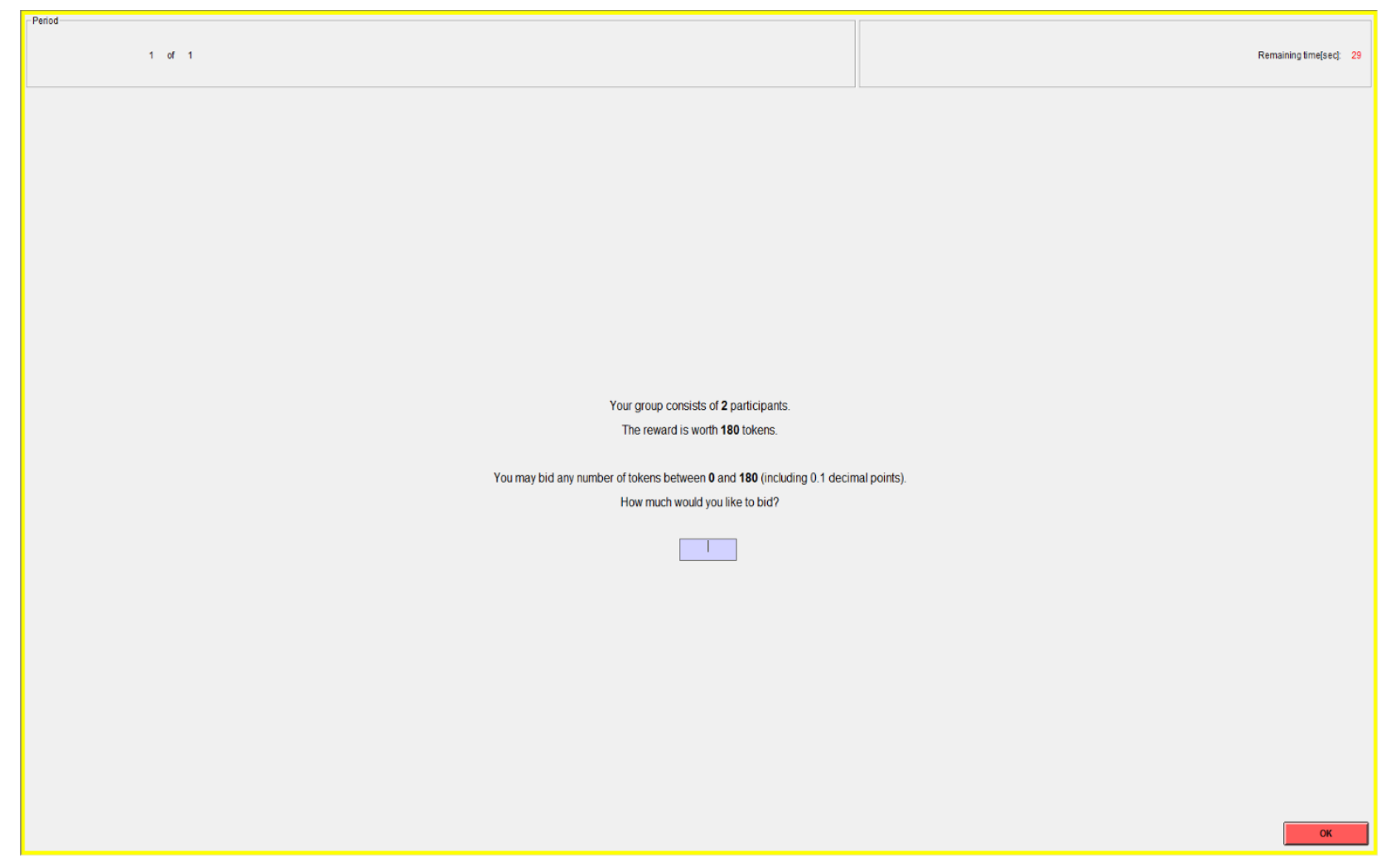

YOUR EARNINGS

For each bid there is an associated cost equal to the bid itself. The cost of your bid is:

Cost of your bid $=$ Your bid

The more you bid, the more likely you are to receive the reward. The more the other participant in your group bid, the less likely you are to receive the reward. Specifically, your chance of receiving the reward is given by your bid divided by the sum of all 2 bids in your group: 


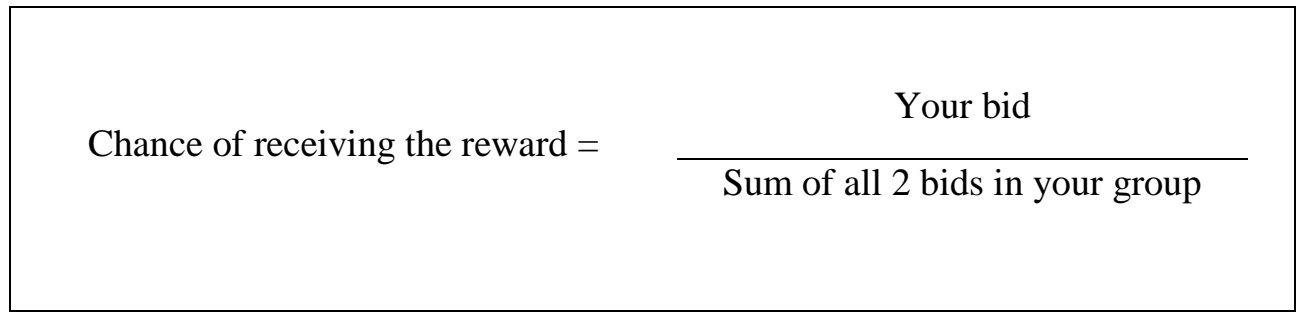

You can consider the amounts of the bids to be equivalent to numbers of lottery tickets. The computer will draw one ticket from those entered by you and the other participant, and assign the reward to one of the participants through a random draw. If you receive the reward, your earnings for the period are equal to your endowment of 180 tokens plus the reward of 180 tokens minus the cost of your bid. If you do not receive the reward, your earnings for the period are equal to your endowment of 180 tokens minus the cost of your bid. In other words, your earnings are:

If you receive the reward: Earnings $=$ Endowment + Reward - Cost of your bid $=180+180-$ your bid

If you do not receive the reward: Earnings $=$ Endowment - Cost of your bid $=180-$ your bid

\section{An Example (for illustrative purposes only)}

Let's say participant 1 bids 30 tokens and participant 2 bids 45 tokens. Therefore, the computer assigns 30 lottery tickets to participant 1 and 45 lottery tickets to participant 2 . Then the computer randomly draws one lottery ticket out of $75(30+45)$. As you can see, participant 2 has the highest chance of receiving the reward: $0.60=\mathbf{4 5 / 7 5}$ and participant 1 has $0.40=30 / 75$ chance of receiving the reward.

Assume that the computer assigns the reward to participant 1, then the earnings of participant 1 for the period are $330=180+180-30$, since the reward is 180 tokens and the cost of the bid is 30 . Similarly, the earnings of participant 2 are $135=180-45$.

At the end of each period, your bid, the sum of all 2 bids in your group, your reward, and your earnings for the period are reported on the outcome screen as shown below. Once the outcome screen is displayed you should record your results for the period on your Personal Record Sheet (page 4) under the appropriate heading. 


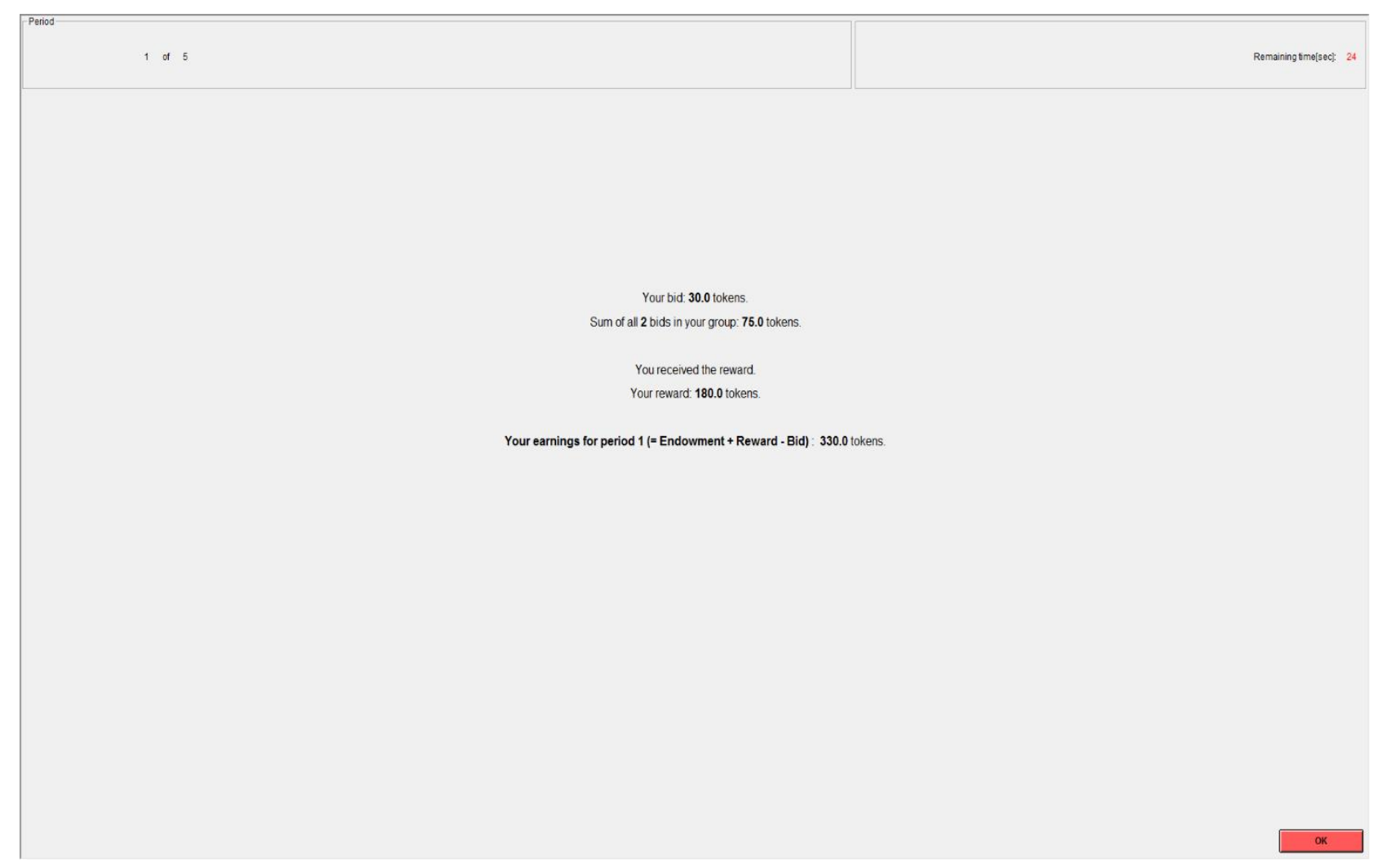

\section{IMPORTANT NOTES}

At the beginning of this part of the experiment you will be randomly grouped with another participant to form a 2-person group. You will not be told which of the participants in this room are assigned to which group.

At the end of the experiment the computer will randomly choose 5 of the 25 periods for actual payment for this part of experiment. You will be paid the average of your earnings in these 5 periods. These earnings in tokens will be converted to cash at the exchange rate of $\mathbf{1}$ token to $\mathbf{3}$ Pence (£0.03) and will be paid at the end of the experiment.

Are there any questions? 


\section{Personal Record Sheet}

( 5 periods from here will be randomly chosen for final payments)

\begin{tabular}{|c||l|l|l|l|}
\hline Period & Your bid & $\begin{array}{c}\text { Sum of all 2 } \\
\text { bids in your } \\
\text { group }\end{array}$ & Your reward & $\begin{array}{l}\text { Your earning } \\
\text { for this period }\end{array}$ \\
\hline 1 & & & & \\
\hline 2 & & & & \\
\hline 3 & & & & \\
\hline 4 & & & & \\
\hline 5 & & & & \\
\hline 6 & & & & \\
\hline 7 & & & & \\
\hline 8 & & & & \\
\hline 9 & & & & \\
\hline 10 & & & & \\
\hline 11 & & & & \\
\hline 12 & & & & \\
\hline 13 & & & & \\
\hline 14 & & & & \\
\hline 15 & & & & \\
\hline 16 & & & & \\
\hline 17 & & & & \\
\hline 18 & & & & \\
\hline 19 & & & & \\
\hline 20 & & & & \\
\hline 21 & & & & \\
\hline 22 & & & & \\
\hline 23 & & & & \\
\hline 24 & & & & \\
\hline 25 & & & & \\
\hline
\end{tabular}


Total Earnings

\begin{tabular}{|l|l|}
\hline Period Chosen & Earnings for this period \\
\hline & \\
\hline & \\
\hline & \\
\hline & \\
\hline & \\
\hline Total & \\
\hline
\end{tabular}

Total earnings from table above:

Average of above earnings: $(1) \div 5$

Earnings from Part 1:

Total earnings $(2)+(3)$

Multiply by exchange rate:

Total payment for the experiment:

$\mathfrak{f}$

(4) $\times \underline{0.03}$ 


\section{QUIZ}

1. Does group composition change across periods in the experiment?

Ans. Yes No

2. What is the value of 1 token in Pence?

Ans. 3 Pence 6 Pence 9 Pence

Questions 3 to 6 apply to the following information.

In a given period, suppose the bids by participants in your group are as follows.

Bid of participant 1: 55 tokens

Bid of participant 2: 70 tokens

3. What is the chance that participant 1 will receive the reward?

Ans.

out of

4. What is the chance that participant 2 will receive the reward?

Ans.

out of

5. If you are Participant 1 and you did not receive the reward what are your earnings this period?

Ans. tokens

6. If you are Participant 2 and you received the reward what are your earnings this period?

Ans. tokens 


\section{EXPLANATIONS FOR QUIZ ANSWERS}

1. Does group composition change across periods in the experiment?

Ans. No

2. What is the value of 1 token in Pence?

Ans. $\quad \underline{3 \text { Pence }}$

3. What is the chance that participant 1 will receive the reward?

Ans. $\quad \underline{55}$ out of $\underline{125}$.

4. What is the chance that participant 2 will receive the reward?

Ans. $\quad \underline{70}$ out of $\underline{125}$.

5. If you are Participant 1 and you did not receive the reward what are your earnings this period?

Ans. $\underline{125}$ tokens $\quad(=$ Endowment - bid $=180-55)$

6. If you are Participant 2 and you received the reward what are your earnings this period?

Ans. 290 tokens $\quad(=$ Endowment + Reward - Bid $=180+180-70)$ 


\section{INSTRUCTIONS - LOSS}

\section{YOUR DECISION}

This part of the experiment consists of $\mathbf{2 5}$ decision-making periods. At the beginning, you will be randomly and anonymously placed into a group of $\mathbf{2}$ participants. The composition of your group will remain the same for all 25 periods. You will not know who your group member is at any time.

Each period both of you will receive an initial endowment of $\mathbf{1 8 0}$ tokens as well as a reward of $\mathbf{1 8 0}$ tokens. Each period, both of you may bid to keep your reward, but only one of you will be able to keep your reward. You may bid any number between $\mathbf{0}$ and 180 (including 0.1 decimal points). An example of your decision screen is shown below.

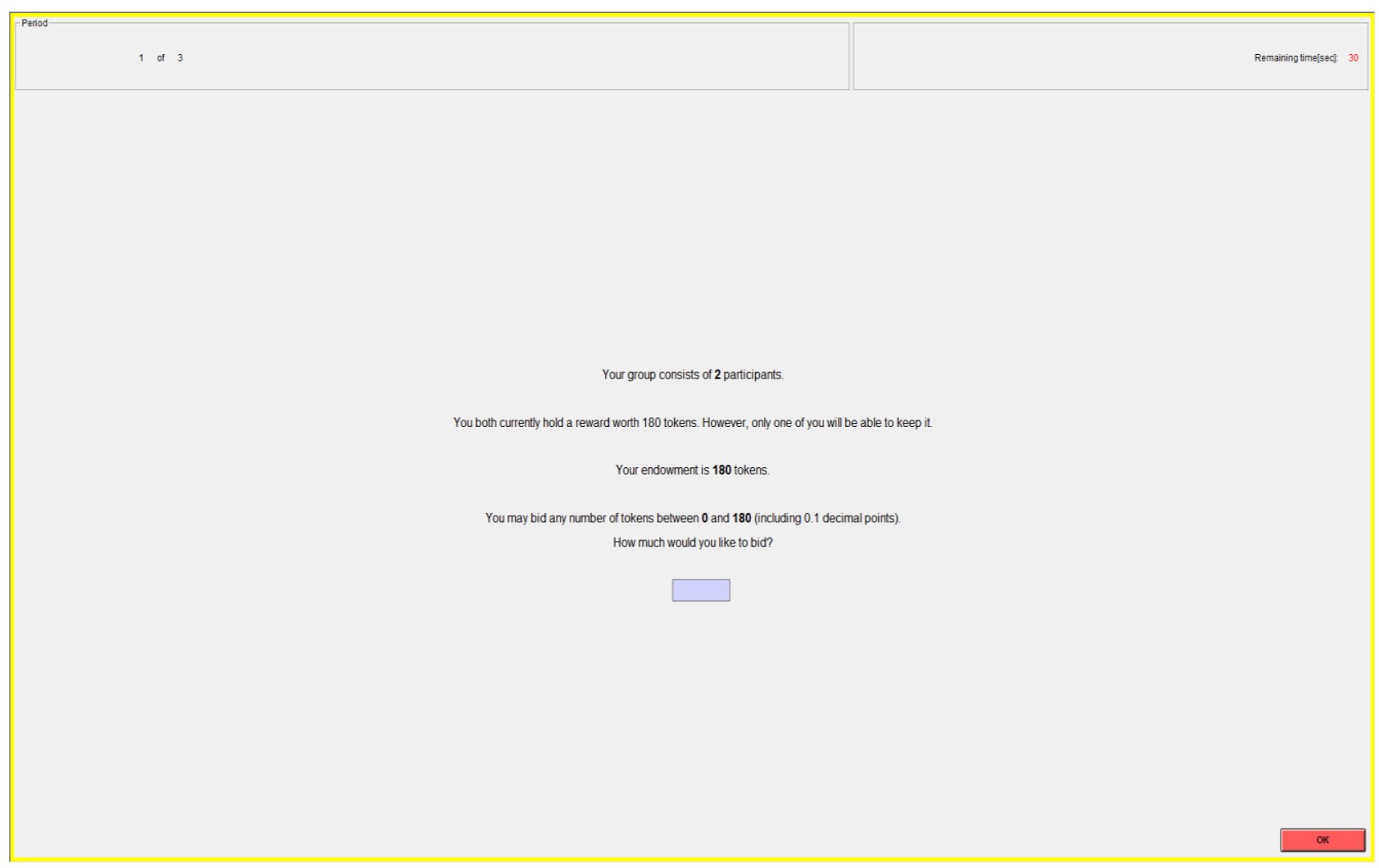

\section{YOUR EARNINGS}

For each bid there is an associated cost equal to the bid itself. The cost of your bid is:

Cost of your bid $=$ Your bid 
The more you bid, the more likely you are to keep the reward. The more the other participant in your group bids, the less likely you are to keep the reward. Specifically, your chance of keeping the reward is given by your bid divided by the sum of all 2 bids in your group:

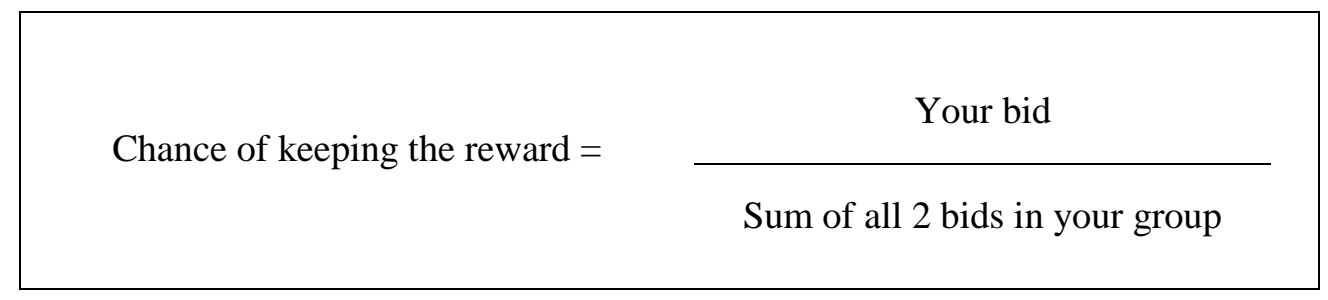

You can consider the amounts of the bids to be equivalent to numbers of lottery tickets. The computer will draw one ticket from those entered by you and the other participant, and decide which one of the participants will keep the reward through a random draw. If you get to keep your reward, your earnings for the period are equal to your endowment of 180 tokens plus the reward of 180 tokens minus the cost of your bid. If you do not get to keep your reward, your earnings for the period are equal to your endowment of 180 tokens minus the cost of your bid. In other words, your earnings are:

If you keep the reward: Earnings $=($ Endowment + Reward $)-$ Cost of your bid -0

$=180+180-$ your bid -0

If you do not keep the reward: Earnings $=($ Endowment + Reward $)-$ Cost of your bid - Reward

$=180+180-$ your bid $-180=180-$ your bid

\section{$\underline{\text { An Example (for illustrative purposes only) }}$}

Let's say participant 1 bids 30 tokens and participant 2 bids 45 tokens. Therefore, the computer assigns 30 lottery tickets to participant 1 and 45 lottery tickets to participant 2 . Then the computer randomly draws one lottery ticket out of $75(30+45)$. As you can see, participant 2 has the highest chance of keeping the reward: $\mathbf{0 . 6 0}=\mathbf{4 5 / 7 5}$ and participant 1 has $\mathbf{0 . 4 0}=\mathbf{3 0} / 75$ chance of keeping the reward.

Assume that the computer decides that participant 1 will keep the reward, then the earnings of participant 1 for the period are $330=(180+180)-30-0$, since the reward is 180 tokens and the cost of the bid is 30 . Similarly, the earnings of participant 2 are $135=(180+180)-45-180$.

At the end of each period, your bid, the sum of all 2 bids in your group, if you could keep your reward, and your earnings for the period are reported on the outcome screen as shown below. Once the outcome screen is displayed you should record your results for the period on your Personal Record Sheet (page 4) under the appropriate heading. 


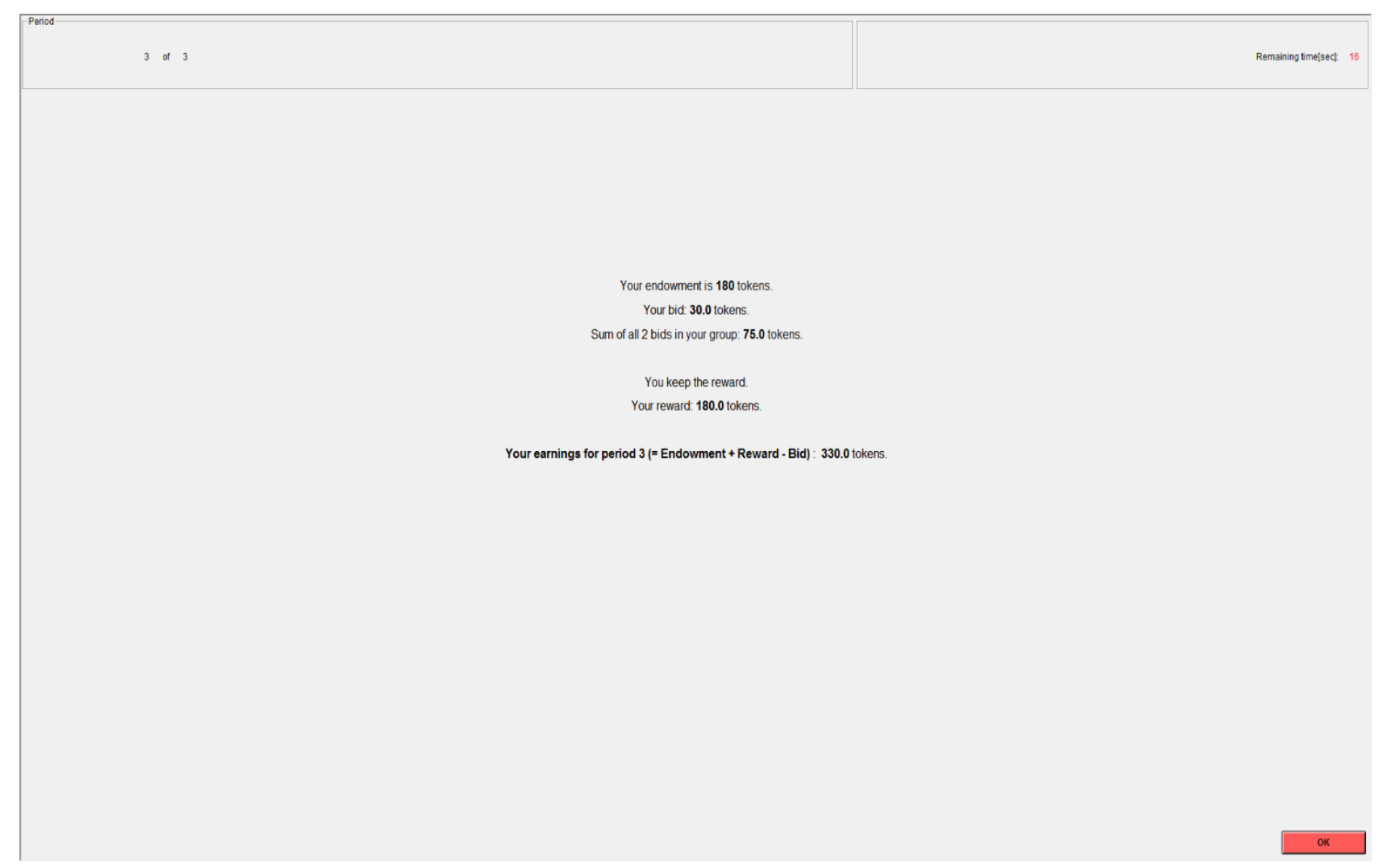

\section{IMPORTANT NOTES}

At the beginning of this part of the experiment you will be randomly grouped with another participant to form a 2-person group. You will not be told which of the participants in this room are assigned to which group.

At the end of the experiment the computer will randomly choose 5 of the 25 periods for actual payment for this part of experiment. You will be paid the average of your earnings in these 5 periods. These earnings in tokens will be converted to cash at the exchange rate of $\mathbf{1}$ token to $\mathbf{3}$ Pence $(£ 0.03)$ and will be paid at the end of the experiment.

\section{Are there any questions?}




\section{Personal Record Sheet}

( 5 periods from here will be randomly chosen for final payments)

\begin{tabular}{|c|c|c|c|c|}
\hline Period & Your bid & $\begin{array}{l}\text { Sum of all } 2 \\
\text { bids in your } \\
\text { group }\end{array}$ & Your reward & $\begin{array}{l}\text { Your earnings } \\
\text { for this period }\end{array}$ \\
\hline 1 & & & & \\
\hline 2 & & & & \\
\hline 3 & & & & \\
\hline 4 & & & & \\
\hline 5 & & & & \\
\hline 6 & & & & \\
\hline 7 & & & & \\
\hline 8 & & & & \\
\hline 9 & & & & \\
\hline 10 & & & & \\
\hline 11 & & & & \\
\hline 12 & & & & \\
\hline 13 & & & & \\
\hline 14 & & & & \\
\hline 15 & & & & \\
\hline 16 & & & & \\
\hline 17 & & & & \\
\hline 18 & & & & \\
\hline 19 & & & & \\
\hline 20 & & & & \\
\hline 21 & & & & \\
\hline 22 & & & & \\
\hline 23 & & & & \\
\hline 24 & & & & \\
\hline 25 & & & & \\
\hline
\end{tabular}


Total Earnings

\begin{tabular}{|l|l|}
\hline Period Chosen & Earnings for this period \\
\hline & \\
\hline & \\
\hline & \\
\hline & \\
\hline & \\
\hline Total & \\
\hline
\end{tabular}

Total earnings from table above:

Average of above earnings: $(1) \div 5$

Earnings from Part 1:

Total earnings $(2)+(3)$

Multiply by exchange rate:

(4) $\times \underline{0.03}$

Total payment for the experiment:

$\underline{\mathfrak{E}}$ 


\section{QUIZ}

1. Does group composition change across periods in the experiment?

Ans. Yes No

2. What is the value of 1 token in Pence?

Ans. 3 Pence 6 Pence 9 Pence

Questions 3 to 6 apply to the following information.

In a given period, suppose the bids by participants in your group are as follows.

Bid of participant 1: 55 tokens

Bid of participant 2: 70 tokens

3. What is the chance that participant 1 will keep the reward?

Ans.

out of

4. What is the chance that participant 2 will keep the reward?

Ans.

out of

5. If you are Participant 1 and you did not keep the reward what are your earnings this period?

Ans. tokens

6. If you are Participant 2 and you kept the reward what are your earnings this period?

Ans. tokens 


\section{EXPLANATIONS FOR QUIZ ANSWERS}

1. Does group composition change across periods in the experiment?

Ans. No

2. What is the value of 1 token in Pence?

Ans. $\quad \underline{3 \text { Pence }}$

3. What is the chance that participant 1 will keep the reward?

Ans. $\quad \underline{55}$ out of $\underline{125}$.

4. What is the chance that participant 2 will keep the reward?

Ans. $\quad \underline{70}$ out of $\underline{125}$.

5. If you are Participant 1 and you did not keep the reward what are your earnings this period?

Ans. $\underline{125}$ tokens $\quad(=$ Endowment - bid $=180-55)$

6. If you are Participant 2 and you kept the reward what are your earnings this period?

Ans. $\underline{290}$ tokens $\quad(=$ Endowment + Reward - Bid $=180+180-70)$ 


\section{INSTRUCTIONS - MIXED}

\section{YOUR DECISION}

This part of the experiment consists of $\mathbf{2 5}$ decision-making periods. At the beginning, you will be randomly and anonymously placed into a group of $\mathbf{2}$ participants. The composition of your group will remain the same for all 25 periods. You will not know who your group member is at any time.

Each period you will receive an initial endowment of $\mathbf{1 8 0}$ tokens. One of you will also start each period with a reward of 180 tokens and the other will start with no reward. These roles will be the same throughout the experiment. Both of you may bid to either keep the reward (if you already have it), or to transfer the reward to you from the other participant (if you do not already have it). You may bid any number between $\mathbf{0}$ and $\mathbf{1 8 0}$ (including 0.1 decimal points). An example of your decision screen is shown below.

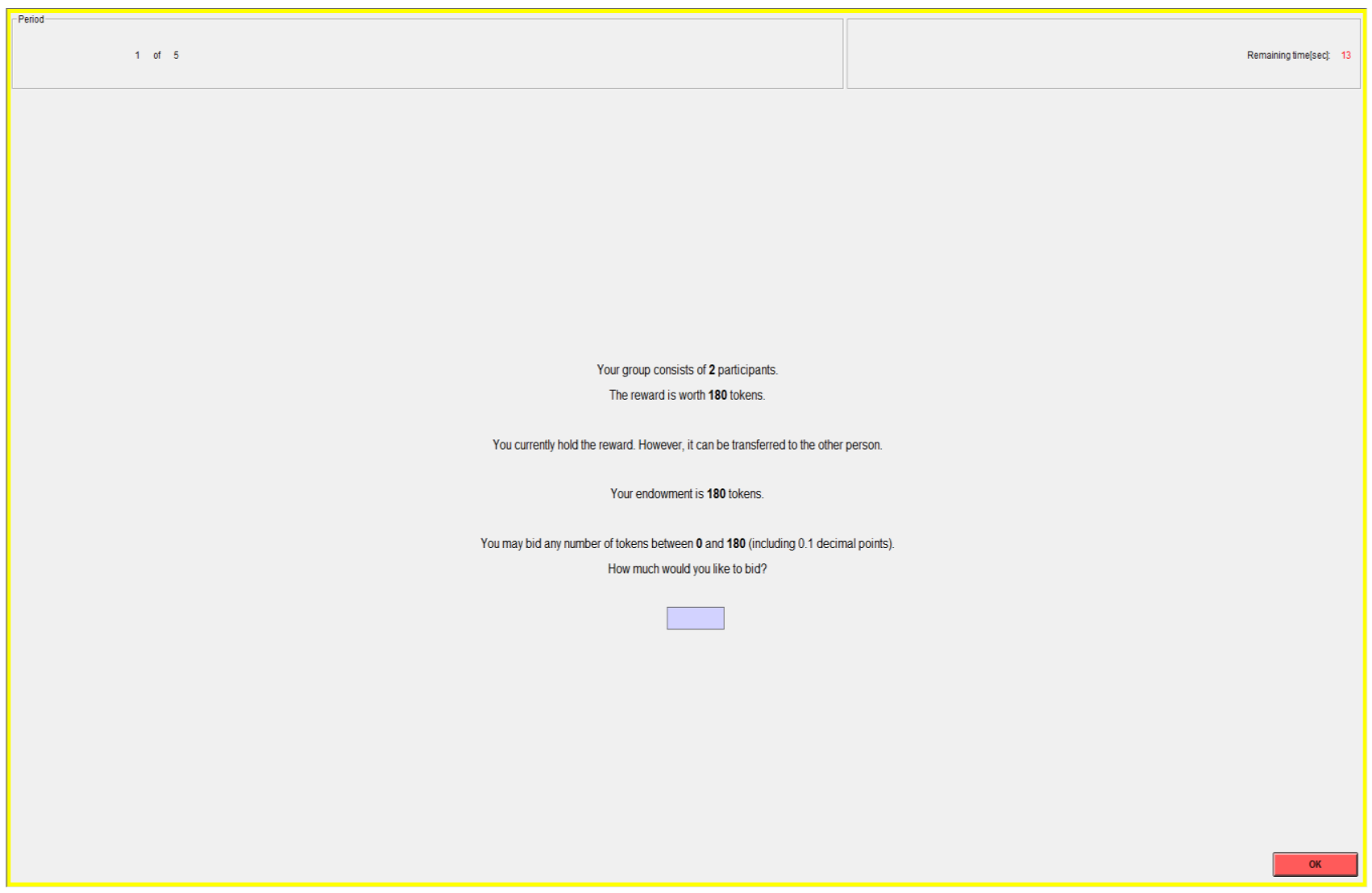

\section{YOUR EARNINGS}

For each bid there is an associated cost equal to the bid itself. The cost of your bid is:

Cost of your bid $=$ Your bid 
If you start with the reward, then the more you bid, the more likely you are to keep the reward. The more the other participant in your group bids, the less likely you are to keep the reward. Specifically, your chance of keeping the reward is given by your bid divided by the sum of all 2 bids in your group:

\begin{tabular}{|cc|}
\hline $\begin{array}{c}\text { Chance of keeping the reward (if you start } \\
\text { with the reward) }=\end{array}$ & Your bid \\
\cline { 2 - 2 } & \\
\hline
\end{tabular}

If you start with no reward, then the more you bid, the more likely you are to transfer the reward to yourself. The more the other participant in your group bids, the less likely you are to transfer the reward to yourself. Specifically, your chance of transferring the reward to yourself is given by your bid divided by the sum of all 2 bids in your group:

Chance of transferring the reward to yourself (if Your bid you do not start with the reward) $=$ Sum of all 2 bids in your group

You can consider the amounts of the bids to be equivalent to numbers of lottery tickets. The computer will draw one ticket from those entered by you and the other participant and either let the reward to stay with the participant who starts with it, or transfer it to the other participant through a random draw.

If you started with the reward and get to keep your reward, your earnings for the period are equal to your endowment of 180 tokens plus the reward of 180 tokens minus the cost of your bid. If you do not get to keep your reward, your earnings for the period are equal to your endowment of 180 tokens minus the cost of your bid. In other words, your earnings are:

If you keep the reward: Earnings $=($ Endowment + Reward $)-$ Cost of your bid -0

$=(180+180)-$ your bid -0

If you do not keep the reward: Earnings $=($ Endowment + Reward $)-$ Cost of your bid - Reward $=(180+180)-$ your bid $-180=180-$ your bid 
If you started with no reward but the reward is transferred to you, your earnings for the period are equal to your endowment of 180 tokens plus the reward of 180 tokens minus the cost of your bid. If the reward is not transferred to you, your earnings for the period are equal to your endowment of 180 tokens minus the cost of your bid. In other words, your earnings are:

If the reward is transferred to you: Earnings $=$ Endowment + Reward - Cost of your bid $=180+180-$ your bid

If the reward is not transferred to you: Earnings = Endowment - Cost of your bid $=180-$ your bid

\section{$\underline{\text { An Example (for illustrative purposes only) }}$}

Let's say participant 1 starts with the reward of 180 tokens and participant 2 starts with no reward. Then participant 1 bids 30 tokens and participant 2 bids 45 tokens. Therefore, the computer assigns 30 lottery tickets to participant 1 and 45 lottery tickets to participant 2 . Then the computer randomly draws one lottery ticket out of $75(30+45)$. As you can see, participant 2 has the highest chance that their ticket is drawn: $0.60=\mathbf{4 5 / 7 5}$ and participant 1 has $0.40=30 / 75$ chance that their ticket is drawn.

Assume that the computer draws a ticket of participant 1, then the reward stays with participant 1 and the earnings of participant 1 for the period are $330=(180+180)-30-0$, since the reward is 180 tokens and the cost of the bid is 30 . Since the reward is not transferred to participant 2, the earnings of participant 2 are $135=180-45$.

If the computer draws a ticket of participant 2, then the reward is transferred to participant 2 and the earnings of participant 1 for the period are $150=(180+180)-30-180$, since the reward is now transferred to participant 2 and the cost of the bid is 30 . Similarly, due to the transfer, the earnings of participant 2 are $315=180-45+180$.

At the end of each period, your bid, the sum of all 2 bids in your group, your reward, and your earnings for the period are reported on the outcome screen as shown below. Once the outcome screen is displayed you should record your results for the period on your Personal Record Sheet (page 5) under the appropriate heading. 


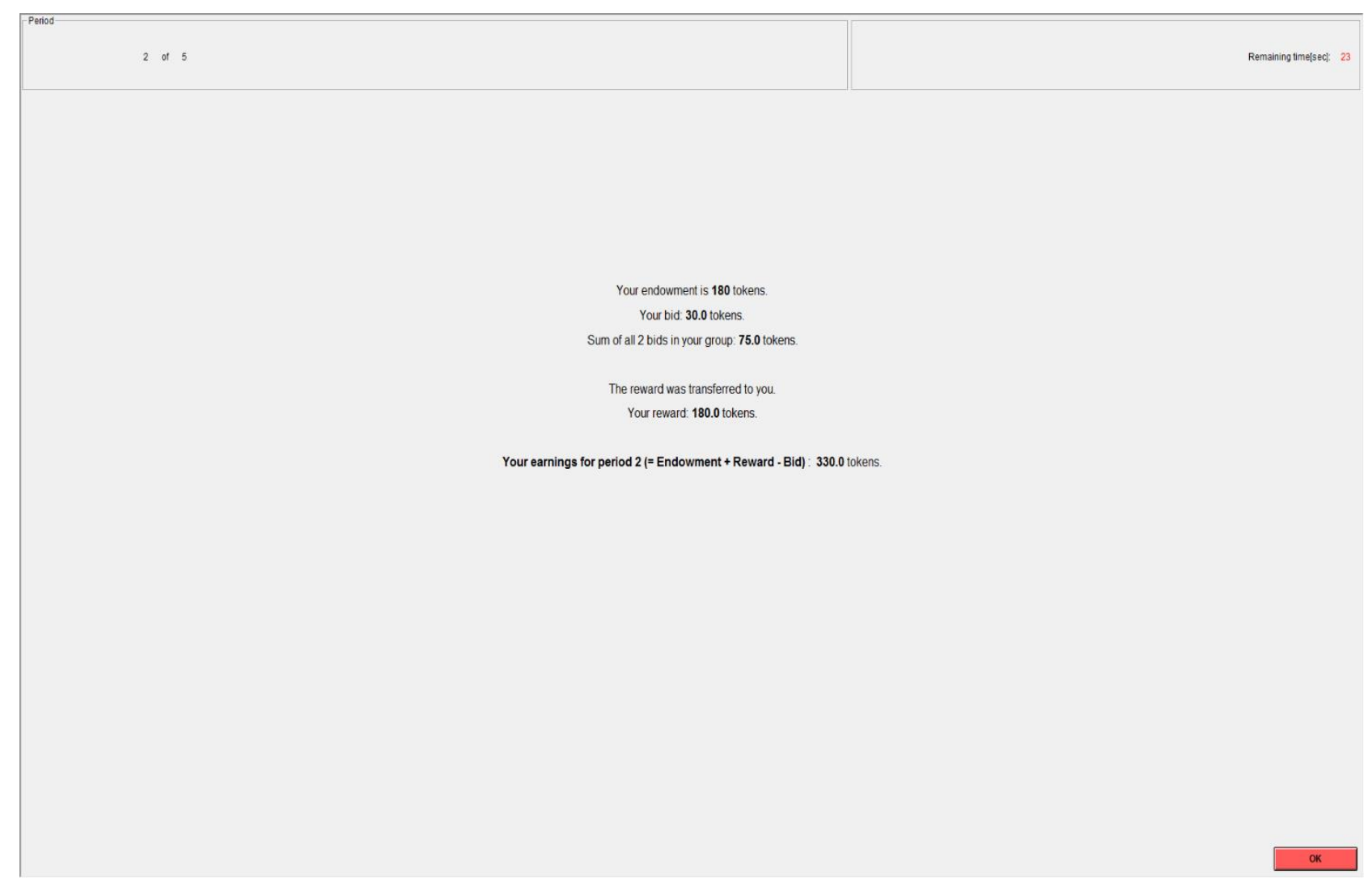

\section{IMPORTANT NOTES}

At the beginning of this part of the experiment you will be randomly grouped with another participant to form a 2-person group. You will not be told which of the participants in this room are assigned to which group.

At the end of the experiment the computer will randomly choose 5 of the 25 periods for actual payment for this part of experiment. You will be paid the average of your earnings in these 5 periods. These earnings in tokens will be converted to cash at the exchange rate of _1_ token to $\mathbf{3}$ _ Pence $(£ 0.03)$ and will be paid at the end of the experiment.

\section{Are there any questions?}




\section{Personal Record Sheet}

( 5 periods from here will be randomly chosen for final payments)

\begin{tabular}{|c||l|l|l|l|}
\hline Period & Your bid & $\begin{array}{c}\text { Sum of all 2 } \\
\text { bids in your } \\
\text { group }\end{array}$ & Your reward & $\begin{array}{l}\text { Your earning } \\
\text { for this period }\end{array}$ \\
\hline 1 & & & & \\
\hline 2 & & & & \\
\hline 3 & & & & \\
\hline 4 & & & & \\
\hline 5 & & & & \\
\hline 6 & & & & \\
\hline 7 & & & & \\
\hline 8 & & & & \\
\hline 9 & & & & \\
\hline 10 & & & & \\
\hline 11 & & & & \\
\hline 12 & & & & \\
\hline 13 & & & & \\
\hline 14 & & & & \\
\hline 15 & & & & \\
\hline 16 & & & & \\
\hline 17 & & & & \\
\hline 18 & & & & \\
\hline 19 & & & & \\
\hline 20 & & & & \\
\hline 21 & & & & \\
\hline 22 & & & & \\
\hline 23 & & & & \\
\hline 24 & & & & \\
\hline 25 & & & & \\
\hline
\end{tabular}


Total Earnings

\begin{tabular}{|l|l|}
\hline Period Chosen & Earnings for this period \\
\hline & \\
\hline & \\
\hline & \\
\hline & \\
\hline & \\
\hline Total & \\
\hline
\end{tabular}

Total earnings from table above:

Average of above earnings: $(1) \div 5$

Earnings from Part 1:

Total earnings $\quad(2)+(3)$

Multiply by exchange rate:

Total payment for the experiment:

$\underline{\mathfrak{E}}$

(4) $\times \quad 0.03$ 


\section{QUIZ}

1. Does group composition change across periods in the experiment?

Ans. Yes No

2. Does role of the player, who starts with a reward of 180 tokens or who starts with no rewards, change across periods in the experiment?

Ans. Yes No

3. What is the value of 1 token in Pence?

Ans. 3 Pence 6 Pence 9 Pence

\section{Questions 4 to 7 apply to the following information.}

In a given period, suppose the roes and the bids by participants in your group are as follows.

Participant 1 starts with a reward of 180 tokens, and participant 2 starts with no reward.

Bid of participant 1: 55 tokens

Bid of participant 2: 70 tokens

4. What is the chance that participant 1 will get to keep the reward?

Ans. out of

5. What is the chance that the reward will be transferred to participant 2 ?

Ans. out of

6. If you are Participant 1 and you did not get to keep the reward what are your earnings this period? Ans. tokens

7. If you are Participant 2 and the reward is transferred to you, what are your earnings this period? Ans. tokens 


\section{EXPLANATIONS FOR QUIZ ANSWERS}

1. Does group composition change across periods in the experiment?

Ans. $\quad \underline{\text { No }}$

2. Does role of the player, who starts with a reward of 180 tokens or who starts with no rewards, change across periods in the experiment?

Ans. Yes No

3. What is the value of 1 token in Pence?

Ans. $\quad \underline{3 \text { Pence }}$

4. What is the chance that participant 1 will get to keep the reward?

Ans. $\quad \underline{55}$ out of $\underline{125}$.

5. What is the chance that the reward will be transferred to participant 2 ?

Ans. $\quad \underline{70}$ out of $\underline{125}$.

6. If you are Participant 1 and you did not get to keep the reward what are your earnings this period?

Ans. $\underline{125}$ tokens $\quad(=$ Endowment + Reward - bid - Reward $=180+180-55-180)$

7. If you are Participant 2 and the reward is transferred to you, what are your earnings this period?

Ans. $\underline{290}$ tokens $\quad(=$ Endowment + Reward $-\operatorname{Bid}=180+180-70)$ 